\title{
The Use of Active Jet Ignition to Overcome Traditional Challenges of Pre-Chamber Combustors Under Low Load Conditions
}

\author{
Michael Bunce ${ }^{* \dagger}$, Alasdair Cairns*, Hugh Blaxill ${ }^{\dagger}$ \\ *University of Nottingham, University Park, Nottingham, NG7 2RD, UK \\ ${ }^{\dagger}$ MAHLE Powertrain LLC, 14900 Galleon Ct., Plymouth, Michigan 48170, USA
}

KEYWORDS: pre-chamber, jet ignition, dilution, lean combustion

\begin{abstract}
The need for advanced combustion technologies for use in future highly efficient powertrains in the automotive sector is well understood. Pre-chamber combustors, a technology with numerous historic examples, are fast becoming a major area of research once again. Pre-chambers are proportionally small partially enclosed chambers where combustion of a small quantity of fuel and air initiates before transferring to the main cylinder and, in spark ignition applications, subsequently igniting the bulk of the fuel and air. Pre-chambers effectively cascade two combustion events in order to increase the ignition energy present in the main combustion event, thereby enabling stable combustion of difficult-to-ignite main chamber mixtures, such as those with high levels of dilution.
\end{abstract}

A traditional weakness of the subset of pre-chamber concepts known as jet igniters is poor low load engine performance. Combustion stability challenges and insufficient spark retard authority under heavily throttled conditions have limited the prospects of commercial implementation of jet ignition in modern engines. This study seeks to evaluate the root cause of these limitations and propose practical solutions that leverage the inherent flexibility of auxiliary fueled (active) jet ignition. Results of these experiments demonstrate the ability of a jet ignition engine to achieve idle and catalyst heating performance consistent with that of modern SI engines, thereby reducing the barriers to commercial implementation.

\section{INTRODUCTION}

The perpetual desire to conserve fuel is driving strong demand for increased efficiency in spark ignition (SI) engines. This desire is manifested in both market and regulatory demands. A method being increasingly explored to accomplish this goal is gasoline lean combustion [1-5]. Homogeneous lean combustion $(1<\lambda<\sim 1.6)$ in modern SI engines has been proven to increase thermal efficiency. It has also, however, been shown to increase nitrogen oxides $\left(\mathrm{NO}_{\mathrm{x}}\right)$ emissions in the near-lean region, necessitating highly efficient $\mathrm{NO}_{\mathrm{x}}$ aftertreatment in order to adhere to 
criteria emissions regulations [6,7]. Homogeneous ultra-lean combustion with $\lambda>1.6$ has demonstrated the ability to both increase thermal efficiency and significantly reduce $\mathrm{NO}_{\mathrm{x}}$ emissions due to the colder cylinder temperatures innate to combustion with high levels of dilution $[7,8]$.

The major limitation in developing lean and ultra-lean combustion systems is the less favorable ignition quality of the mixture. This has necessitated the development of higher energy ignition sources $[9,10]$. A pre-chamber combustor application is one such technology. SI engines that utilize pre-chambers generally retain the spark plug but relocate it to the pre-chamber and repurpose it as the ignition source for the air-fuel charge present in the pre-chamber. Products from this combustion event are then transferred to the main chamber through an orifice(s) or valve, thermo-chemically igniting the main chamber air-fuel charge. This provides greater ignition energy compared to that of a standard single-point spark plug.

Pre-chamber combustion concepts have demonstrated the potential for stable main chamber combustion at higher levels of dilution than are allowable in typical SI engines [11,12]. They have also demonstrated the ability to counter the loss of ignitability of the lean charge. This capability results in an extension of the lean limit of the engine. As the air-fuel charge is further enleaned, the portion of this charge entering the pre-chamber becomes regressively ignitable with a standard spark plug. Auxiliary fueling in the pre-chamber can compensate for the enleanment of this incoming charge, extending the lean limit further and enabling the engine to operate in an ultra-lean combustion mode. Direct injection (DI) fuel injector technology has removed one of the major technological barriers and renewed interest in this concept [13], as have modern machining techniques that enable smaller pre-chamber volumes than were previously allowable.

In addition to auxiliary fuel injection in the pre-chamber, auxiliary air injection has also been incorporated into active pre-chambers $[14,15]$. These systems are ideal for extending the EGR dilution limit of the main chamber. Since main chamber contents are transferred to the prechamber during the compression stroke, auxiliary air injection can compensate for the low proportion of air in the incoming charge. These systems present practical challenges, such as packaging and the need for a high pressure air delivery system, which must be overcome for production applications.

\section{MAHLE JET IGNITION COMBUSTION SYSTEM}

MAHLE Powertrain has been developing a pre-chamber combustor concept known as MAHLE Jet Ignition ${ }^{\circledR}$ (MJI) since 2009 through the research of Attard, et al $[11,13,16]$ and this author $[1,2,17,18]$. MJI was originally conceived as a non-hydrogen fueled variant of the HAJI concept. In an effort to make the technology more commercially viable, MJI research focused on developing a liquid gasoline variant for passenger car applications, using a single fuel source to supply both pre-chamber and main chamber fuel injectors. The key differentiator between MJI and its antecedents is the incorporation of modern DI fuel injector technology in the prechamber. The use of a micro-flow DI fuel injector allows for precise, consistent metering of small quantities of fuel each cycle and precise targeting of the fuel spray within the pre-chamber. The high pressure capabilities of modern DI fuel injection systems also enable relatively late fuel injection in the pre-chamber which in turn allows the fuel strategy to exploit the local charge motion interior to the pre-chamber during the compression stroke. This innovation to the jet ignition concept is viewed as critical for 1) successful operation with a liquid pre-chamber fuel, 
and 2) efficient, judicious use of the pre-chamber fuel in order to ensure a strong system efficiency increase. The MJI pre-chamber prototype assembly is displayed in Fig. 1. Figure 2 illustrates the importance of precise control over pre-chamber fuel quantity by displaying the sensitivity of engine efficiency to minute changes in pre-chamber injected fuel quantity.
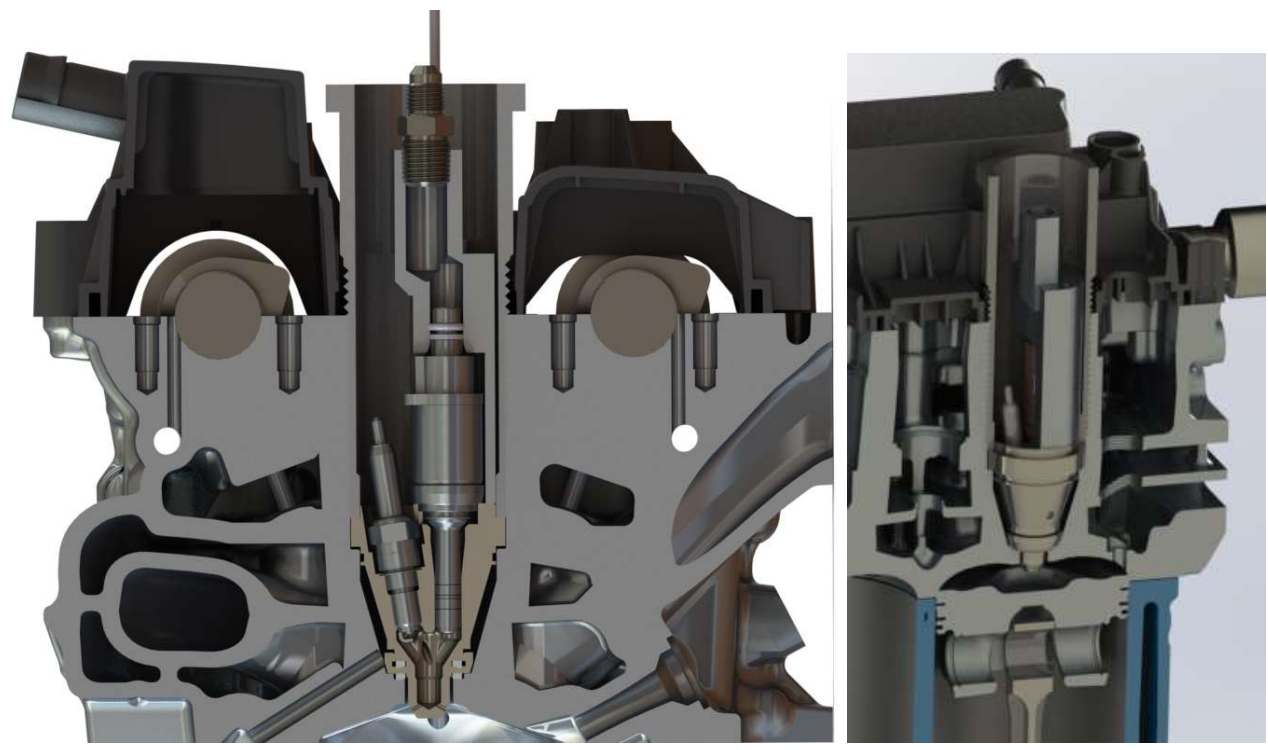

Figure 1. Cutaway of the MJI pre-chamber (left) and MJI pre-chamber assembly (right) in a typical passenger car engine cylinder head.

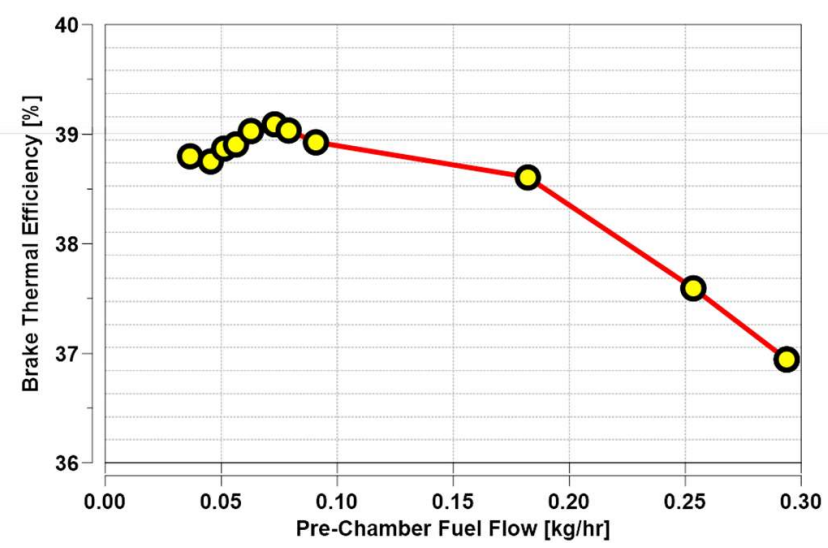

Figure 2. Brake thermal efficiency trends with pre-chamber fuel injection quantity, 1.5L 3cylinder engine, compression ratio $=15.1$, speed $=3000 \mathrm{rpm}$, brake mean effective pressure $=10$ bar, lambda $=1.7$.

MJI incorporates the characteristics of many jet ignition concepts researched since the early 1990 s, namely a small volume pre-chamber $(<5 \%$ of the clearance volume) and a multi-orifice nozzle with orifice diameters that promote a high degree of flame quenching. These characteristics are common to both passive and active jet ignition variants. The quenching and re-ignition process was confirmed through images taken from an optically accessible engine, and confirmed using a computational fluid dynamics (CFD) combustion simulation that was correlated to experimental engine test data [18]. Images from the optical engine are shown in Fig. 3. A CFD model depiction of the jet ignition process is displayed in Fig. 4. 

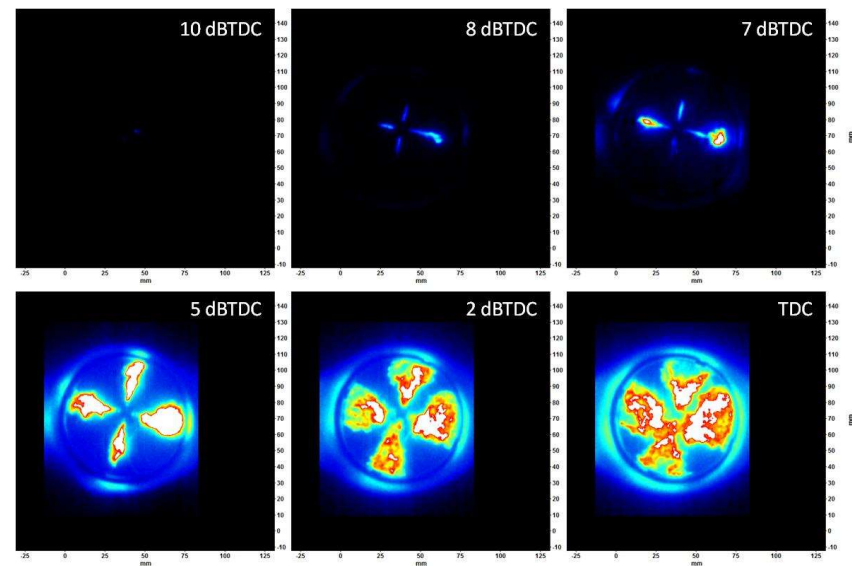

Figure 3. Chemiluminescence high speed images of the jet ignition process (Speed: 1500 rpm, IMEPg: 5.5 bar, $\lambda=1.2$, CR10) taken from an optically accessible engine.

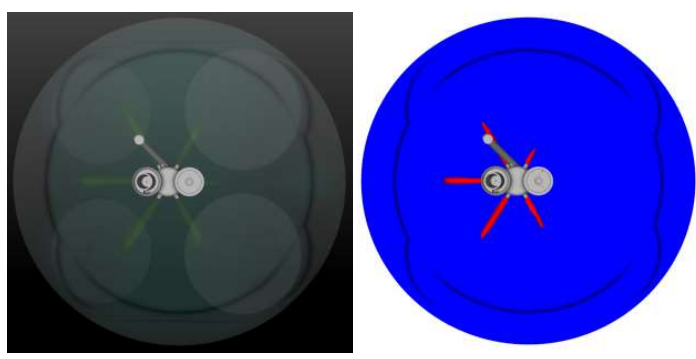

a) -9 CAD
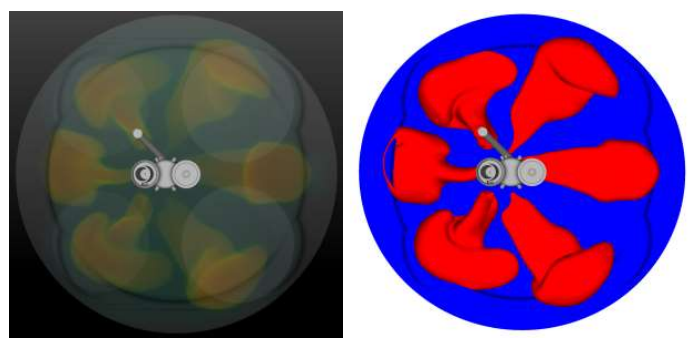

b) $2 \mathrm{CAD}$

Figure 4. CFD combustion model temperature visualization showing main chamber combustion event before (top) and after (bottom) TDC. Left: temperature range (0-2400K), Right: Isosurface@1500K.

Development of the liquid fueled pre-chamber concept did indeed prove challenging. Initial research was plagued by significant wall wetting resulting in rapid plugging of the pre-chamber fuel injector. Combustion in each cylinder also proved to be more sensitive to pre-chamber internal geometry and fuel injector nozzle variation than did that of the gaseous-fueled concept [18]. Figure 5, an image of the fuel injection event taken from the CFD model, illustrates the challenge associated with optimizing a liquid fuel injection concept, namely the potential for significant wall wetting. 

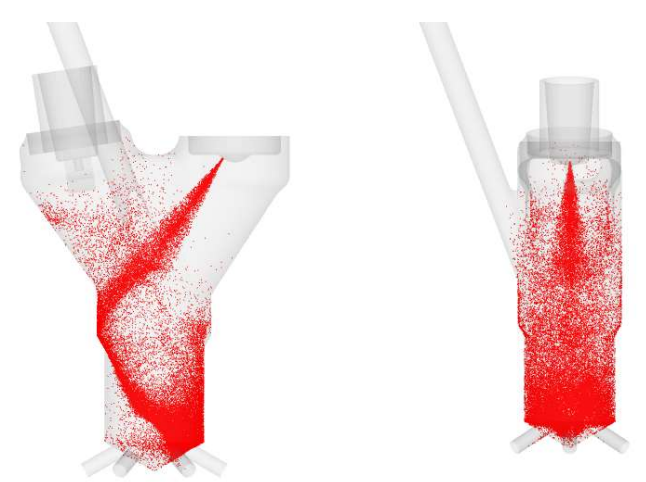

\section{Figure 5. Front and side view of spray pattern within a MJI pre-chamber, 10 CAD after injection.}

Ultimately patents were developed concerning the geometric features of the pre-chamber and the fuel spray / charge motion interaction of a liquid gasoline-fueled pre-chamber concept. Peak brake thermal efficiency published to-date in a MJI engine is $>42 \%$ [1], representing an increase of approximately $15 \%$ above the highest reported comparable production SI engine at the time, and $10 \%$ above the highest reported production-intent SI engine at the time of this writing.

\section{APPLICABILITY ACROSS ENGINE MAP}

Recently jet ignition has become a popular research topic for passenger car applications again, with many engine manufacturers and others presenting results. The authors' research has demonstrated that passive systems in particular require minimal modifications to existing engine and peripheral system architectures and are therefore good candidates to enter the market in the short term. To operate an engine with the high levels of dilution associated with active systems represents a more fundamental shift away from modern SI engine usage; therefore active systems are likely to be introduced after passive systems enter the market.

As with most emerging combustion technologies, challenges remain. Through the authors' research, and through familiarity with those of other groups researching jet ignition, one main area has been identified that needs to be addressed in order to ensure robustness of the technology to the demands of modern SI engines [14,19]. This is performance at low load operation, particularly catalyst heating conditions. This is an impediment to developing a jet ignition concept that can effectively span the entire engine operating map.

Historically jet ignition concepts have had limited success achieving acceptable combustion stability under low load operation including idle and catalyst light-off operation [20,21]. These conditions require a high degree of spark retard capability, a capability that is typically lacking with jet ignition concepts.

The most impactful challenge posed by the low load spark retard limitation concerns the ability to heat the aftertreatment catalysts upon cold start. The tailpipe emissions produced by vehicles are more significant during the startup phase prior to catalyst light-off than they are at any other point in a legislated drive cycle. Catalysts require heat input to work effectively. Prior to achieving a high temperature light-off condition a large proportion of the engine-out emissions pass through un-catalyzed or uncaptured to the tailpipe. Aggressive warm up of the catalysts is therefore critical to ensuring that the vehicle can meet legislated emissions requirements. The common solution to ensure rapid heat input to the catalyst is to retard spark timing to such a 
degree that combustion occurs exclusively during the expansion stroke. The much later burning process results in both increased exhaust temperature and increased exhaust flow. The latter results from the non-optimal combustion phasing requiring de-throttling to compensate for the poor thermal efficiency. This poor thermal efficiency is purposeful since a large proportion of the combustion process has minimal contribution to torque and instead is used largely to generate heat. Spark retard, and its ability to generate high exhaust enthalpy, therefore is an essential element of catalyst heating operation, which makes pre-chambers' nominal lack thereof a major concern.

The present study seeks to quantify the spark retard challenge relative to target cold start spark retard (CSSR) targets, and to evaluate optimization pathways that can mitigate this challenge.

\section{EXPERIMENTAL APPARATUS}

The jet ignition engine used as the research platform in the present study is an in-line turbocharged 3-cylinder based on the 1.2 liter MAHLE DI3 Downsizing demonstrator whose development has been well documented $[22,23]$. The stroke has been elongated to increase the displacement to 1.5 liters. It is able to be converted to either DI or port fuel injection (PFI) for the main chamber fueling and is used in the PFI configuration for this study. Engine specifications are listed in Table 1 and the engine is depicted in Figure 6.

The engine incorporates an identical pre-chamber assembly into each cylinder. The prechamber assembly houses a fuel injector, spark plug, and high-speed pressure transducer (main chamber - Kistler 6041, pre-chamber - AVL GH14). The pre-chamber body and nozzle are separate pieces to allow for the use of interchangeable hardware. Pre-chamber and nozzle geometric specifications were determined using patented relationships [17,24] developed as part of previous projects $[1,2,18]$.

Engine speed is controlled by a motoring dynamometer. At each operating condition, the engine control unit (ECU) varies throttle position and main chamber fuel quantity to achieve a commanded brake mean effective pressure (BMEP) at the commanded overall lambda in a closed loop mode. Commanded lambda is controlled via a wide-band oxygen $\left(\mathrm{O}_{2}\right)$ sensor located in the exhaust manifold. This sensor reading is verified with a calculated lambda from measured exhaust emissions and from air flow and fuel flow measurements. Exhaust emissions are measured using an AVL AMA i60 emissions bench that contains carbon dioxide $\left(\mathrm{CO}_{2}\right)$, carbon monoxide (CO), total hydrocarbons (THC), methane $\left(\mathrm{CH}_{4}\right), \mathrm{O}_{2}$, and $\mathrm{NO}_{\mathrm{x}}$ analyzers. As the engine is enleaned beyond $\lambda=1.3$, the pulsewidth of the pre-chamber DI is increased to maintain the coefficient of variation (COV) of gross indicated mean effective pressure (IMEPg) less than $3 \%$. Main chamber and pre-chamber fuel flow rates are measured using a MicroMotion Coriolis flow meter and Bronkhorst M13 Coriolis flow meter, respectively. Unless otherwise stated all efficiency and fuel consumption metrics are calculated using total fuel flow to both chambers.

Both main chamber PFI and pre-chamber auxiliary DI fuel pressure are provided externally in the test cell and are nominally set to 4 bar and 100 bar, respectively. The friction penalty for operating a fuel pump to feed the high pressure pre-chamber DI is small due to the low fuel flow rate used by the pre-chamber. Using a fuel pressure of 100 bar with a conservative fuel pump efficiency of $60 \%$, the resulting impact on the brake efficiency values presented here would be less than $0.1 \%$. This friction penalty is disregarded for the purposes of this study. 
Table 1. Engine specifications

\begin{tabular}{|c|c|}
\hline Configuration & In-line 3 cylinder \\
\hline Displaced volume & $1500 \mathrm{~cm}^{3}$ \\
\hline Stroke & $92.4 \mathrm{~mm}$ \\
\hline Bore & $83 \mathrm{~mm}$ \\
\hline Compression Ratio & $14: 1$ (for this study) \\
\hline Number of Valves & 4 \\
\hline Injection & PFI main chamber, DI pre-chamber \\
\hline Fuel & Pump Grade Premium Gasoline (both \\
\hline Number of Pre-Chamber Orifices & $1.0 \mathrm{~cm}^{3}$ \\
\hline Pre-Chamber Volume & Flat-top with valve cutouts \\
\hline Piston Geometry & Pent-roof with offset pre-chamber \\
\hline Cylinder Head Geometry & Variable-geometry turbocharger \\
\hline Boost System &
\end{tabular}
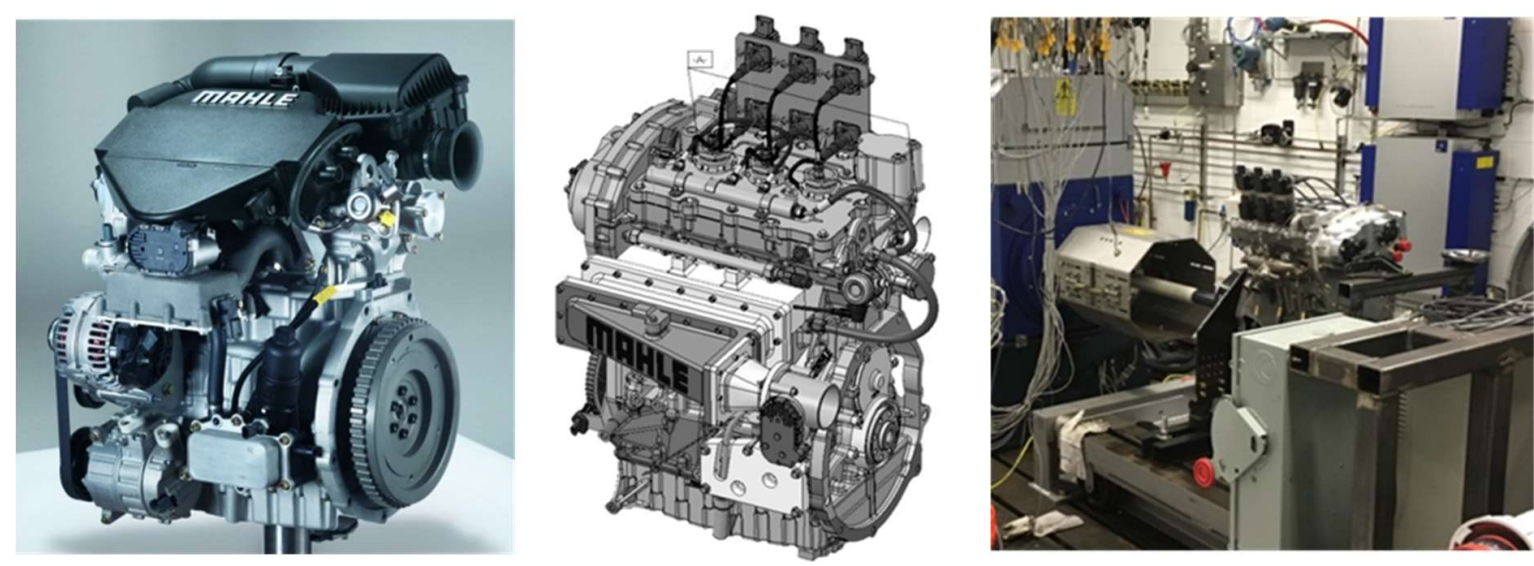

Figure 6. Di3 engine (left) and MJI3 engine (middle, right).

For targeted experiments, a Cambustion fast carbon dioxide $\left(\mathrm{CO}_{2}\right)$ analyzer is used to sample contents directly from the pre-chamber during fired engine operation. The resulting crank angleresolved $\mathrm{CO}_{2}$ trace is used to calculate a residual gas fraction inside the pre-chamber at time of spark.

To supplement the experimental results, CFD combustion simulations are performed using commercially available Converge CFD code with adaptive mesh refinement. Initial and boundary conditions are provided by measured data from the engine where available.

An Air Flow Rig was used to evaluate tumble ratio and swirl number of several charge motion variants of the engine. The Air Flow Rig forces air to flow through the cylinder head, while valve lift is adjusted statically in $1 \mathrm{~mm}$ increments. Tumble ratio and swirl number are calculated by integrating the area under the resulting non-dimensional tumble vs. lift and swirl vs. lift curves, respectively. The Air Flow Rig is shown in Fig. 7. 


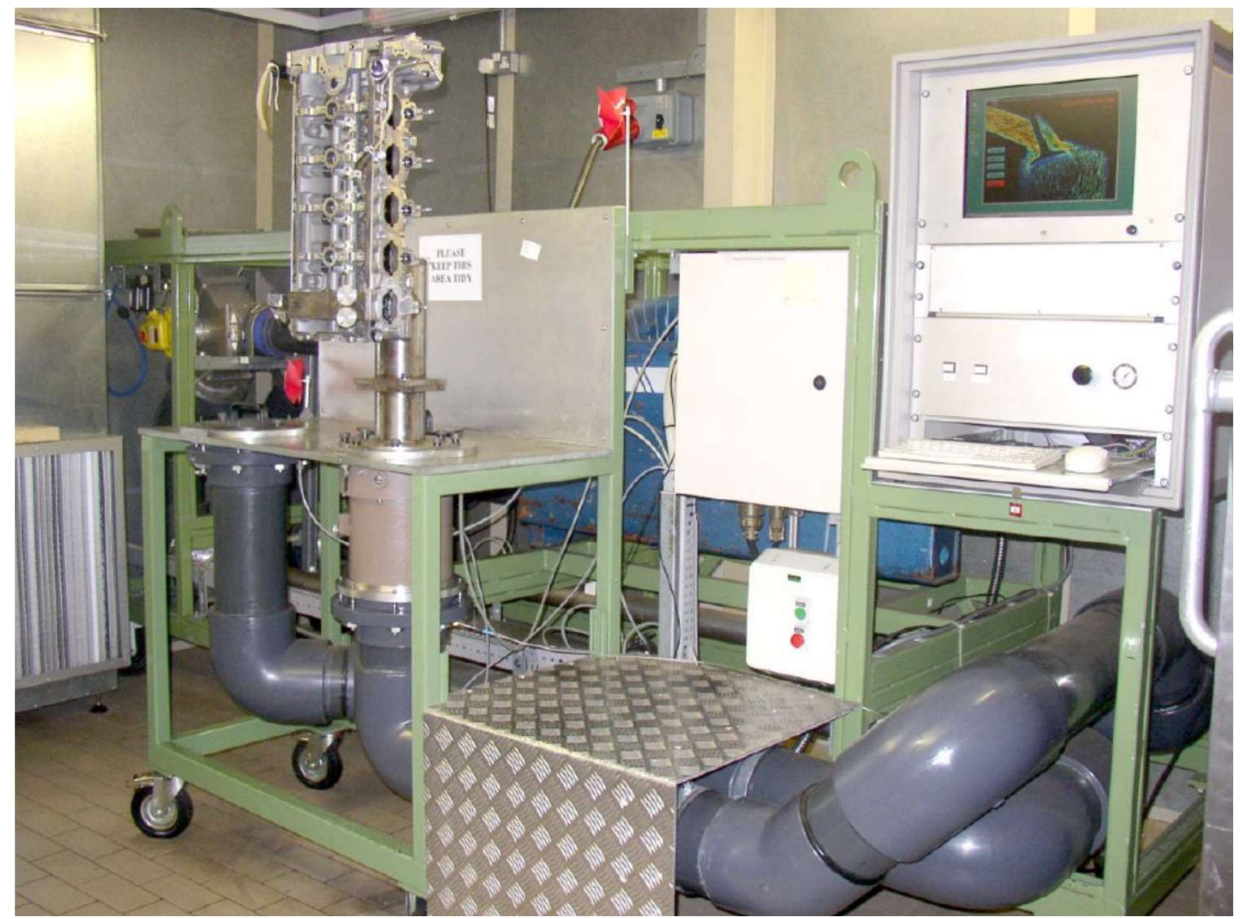

Figure 7. Air Flow Rig.

Four charge motion cases were evaluated: baseline, increased tumble, introduction of swirl, and a combination of swirl and tumble. Charge motion differences from the baseline were induced through the use of plate inserts into each of the intake ports (Fig. 8). The relative change in tumble ratio and swirl number with respect to the baseline (no inserts) port are listed in Table 2.

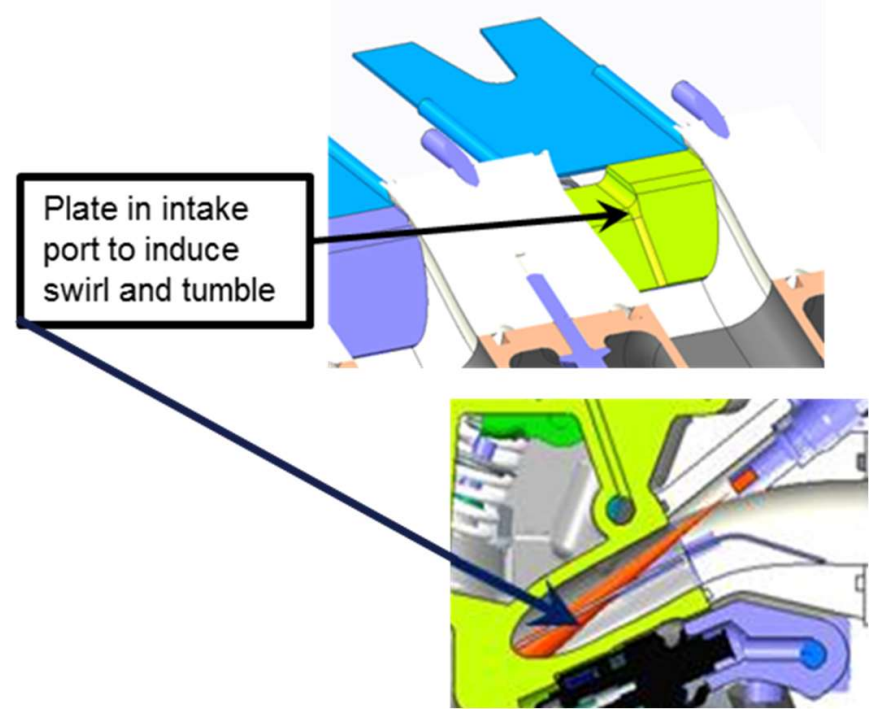

Figure 8. Illustration of tumble plate insert in $1.5 \mathrm{~L}$ jet ignition engine. 
Table 2. Relative change in tumble ratio and swirl number with various intake port insert configurations, relative to the baseline configuration.

\begin{tabular}{|c|c|c|}
\hline Configuration & $\begin{array}{c}\text { Relative Tumble } \\
\text { Ratio }\end{array}$ & $\begin{array}{c}\text { Relative Swirl } \\
\text { Number }\end{array}$ \\
\hline Baseline & - & - \\
\hline Tumble & $+\mathbf{1 3 \%}$ & $-\mathbf{2 5 \%}$ \\
\hline Swirl & $\mathbf{- 3 9 \%}$ & $+1075 \%$ \\
\hline Swirl+Tumble & $+13 \%$ & $+75 \%$ \\
\hline
\end{tabular}

\section{METHODOLOGY}

CFD simulations are performed in order to establish a qualitative understanding of mass transfer dynamics between the pre-chamber and the main chamber under fired conditions. Using $\mathrm{CO}_{2}$ as a proportional surrogate for residual gas fraction in the pre-chamber, observations are made regarding the evolution of $\mathrm{CO}_{2}$ in the pre-chamber from intake valve opening to spark timing. This behavior is compared to experimental data obtained using the fast $\mathrm{CO}_{2}$ direct sampling from the pre-chamber.

Two methods of sampling directly from the pre-chamber were employed and the results were compared for validation purposes. In the sampling valve method, a fast response solenoid valve was connected to a port that broke through to the pre-chamber volume. The valve was commanded open and closed, allowing a small volume of pre-chamber contents to be sampled by the $\mathrm{CO}_{2}$ analyzer. Care was taken to ensure that the proper minimum amount of sample gas was provided to the analyzer, and the time during which the valve sampled was swept throughout the cycle until reasonable convergence was achieved.

In the continuous sampling method (Fig. 9), the analyzer probe was connected directly to a port at the top of the pre-chamber body. A thin capillary connected this port to the pre-chamber volume. The analyzer constantly sampled pre-chamber contents throughout the cycle. The resulting $\mathrm{CO} 2$ trace was used to calculate residual gas fraction inside the pre-chamber.

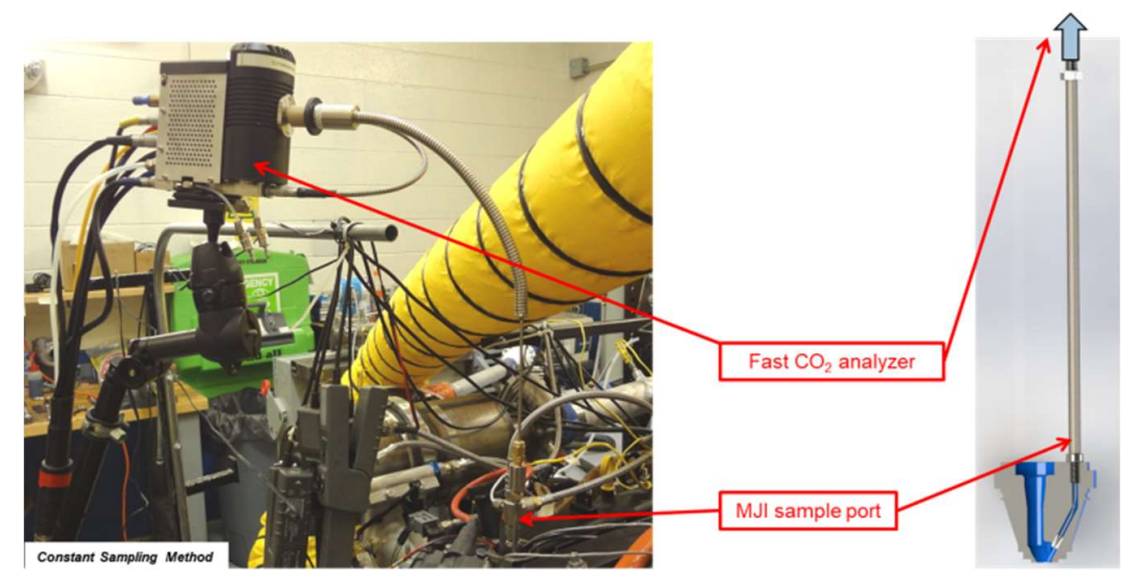

Figure 9. Constant sampling method for measuring pre-chamber residual fraction. 
Experiments were performed to examine the influence that various pre-chamber parameters have on in-pre-chamber residual gas fraction. These parameters include auxiliary fueling quantity and angle of injection. Based on the CFD and fast sampling results, a hypothesis is formulated as to the potential cause of low load operation challenges with pre-chambers.

The engine is used to quantify the extent of the low load operation challenges, with inadequate spark retard at the CSSR condition being a particular concern. A mitigation methodology informed by the CFD and fast sampling results is validated on the engine at this condition.

\section{RESULTS}

Pre-chamber concepts have historically faced challenges under low load operation. This challenge manifests in two distinct ways: poor combustion stability at heavily throttled low loads (less than approximately 2 bar BMEP) and poor spark retard capability at loads consistent with idle and CSSR operation. The well documented efficiency benefits of jet ignition at part load and high load $[1,2,10]$ cannot be practically translated to non- and mild hybrid engine applications unless a solution to the low load pre-chamber limitation is identified.

\section{Pre-Chamber Gas Exchange}

Most jet ignition concepts, including MJI, do not include any direct introduction of oxygen in the pre-chamber, instead relying on induced gas exchange between pre-chamber and main chamber to provide sufficient oxygen for combustion. This gas exchange process is driven by pressure differentials amongst intake and exhaust ports, pre-chamber, and main chamber throughout the 4-stroke engine cycle. Figure 10 depicts the gas exchange process as described by a CFD simulation of a lean part load operating condition.

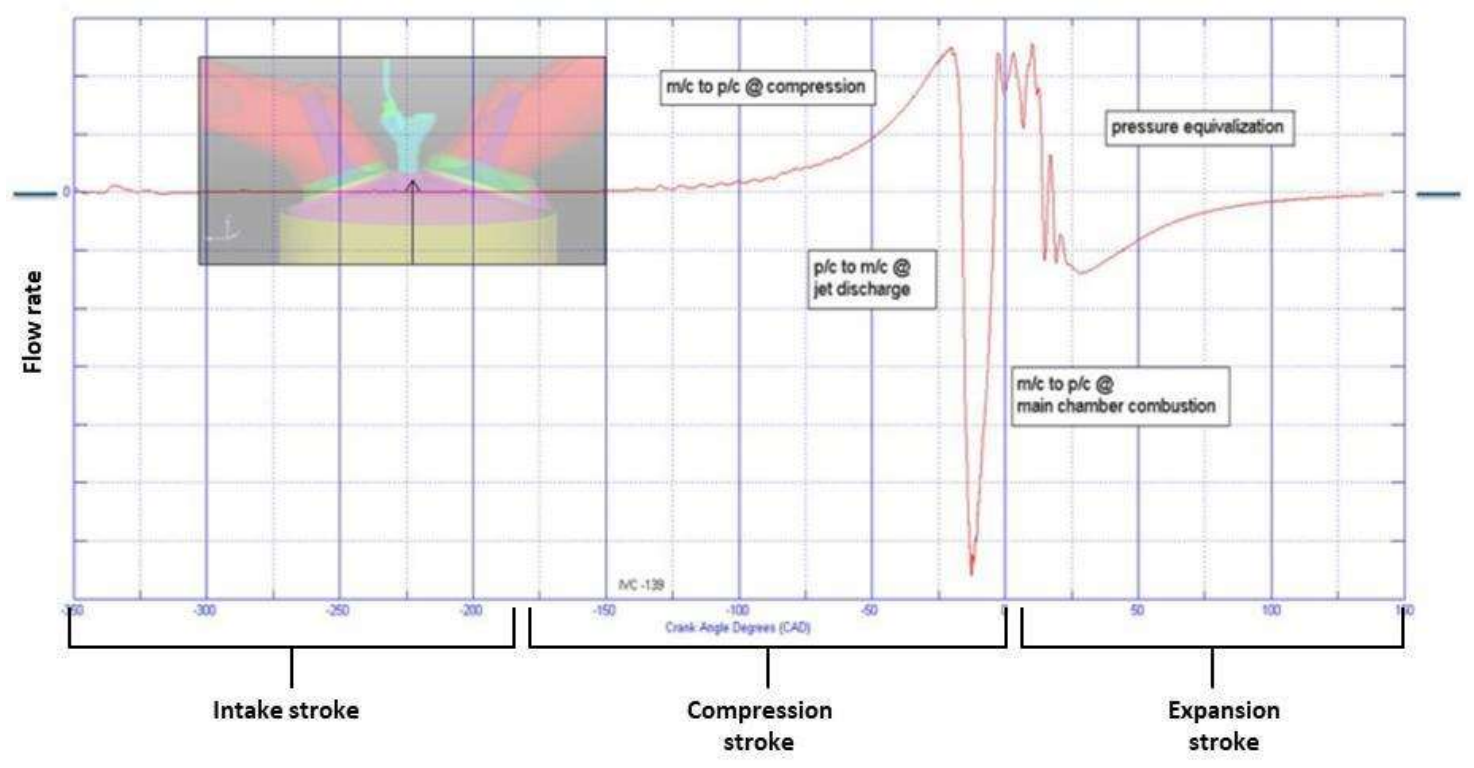

Figure 10. Example mass flow between pre-chamber and main chamber; $1500 \mathrm{rpm}, 5.5$ bar BMEP, $\lambda=1$.

Figure 11 displays the CFD simulated oxygen $\left(\mathrm{O}_{2}\right)$ and $\mathrm{CO}_{2}$ mass fractions inside the pre- 
chamber for a representative part load cycle. The intake valve opening event is when $\mathrm{O}_{2}$ is reintroduced into the system. The $\mathrm{O}_{2}$ fraction then rises in the pre-chamber despite the downward motion of the piston during this phase. The discontinuities apparent in the $\mathrm{O}_{2}$ mass fraction trace correspond to events during the intake process, such as valve fully open and start of valve ramp down, indicating that valve position has a substantial influence on $\mathrm{O}_{2}$ filling of the pre-chamber. It should be noted that there is an increase in $\mathrm{O} 2$ mass in the pre-chamber during the intake stroke and prior to Bottom Dead Center (BDC) being achieved. This result indicates a complex charge interaction between pre-chamber and main chamber during this period that is driven by pressure dynamics within the combustion chamber and possibly charge motion. Any inhibitions during this period, such as reduced intake pressure due to heavy throttling, will negatively impact the pre-chamber $\mathrm{O}_{2}$ filling process.

With the intake valve closed and piston motion upward during the compression stroke, the remainder of the $\mathrm{O}_{2}$ filling process occurs, which in turn dilutes the $\mathrm{CO}_{2}$ mass fraction in the prechamber. With sufficient $\mathrm{O}_{2}$ present, fuel can then be separately added to ensure a pre-chamber lambda within the ignitability limits of the spark plug.

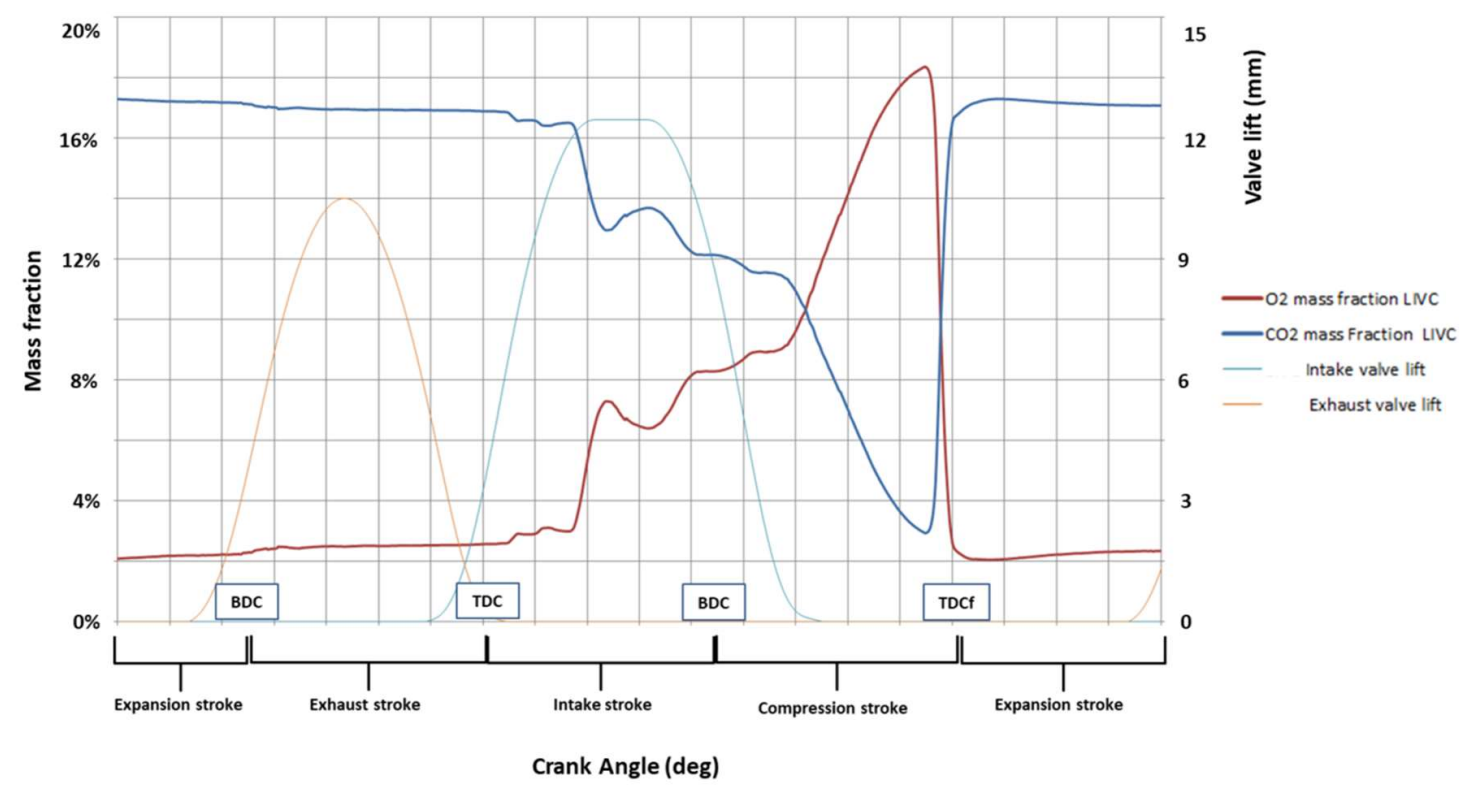

Figure 11. Example of $\mathrm{O}_{2}$ and $\mathrm{CO}_{2}$ mass fraction evolution in the pre-chamber; 1500 rpm, 5.5 bar BMEP, $\lambda=1$.

Figure 12 displays the experimental results of the fast $\mathrm{CO}_{2}$ sampling of contents in the prechamber during fired engine operation. The structure of the $\mathrm{CO}_{2}$ trace mirrors that of the Cambustion guideline $\mathrm{CO}_{2}$ trace for a conventional SI engine. There is a discernable step in the $\mathrm{CO}_{2}$ trace that occurs between the measurement of the pre-combustion $\mathrm{CO}_{2}$ mass fraction and the post-combustion $\mathrm{CO}_{2}$ mass fraction (immediately after the minimum $\mathrm{CO}_{2}$ value is reached, accounting for measurement transport delay) that possibly indicates $\mathrm{CO}_{2}$ mass fraction resulting from the initial pre-chamber combustion event. 


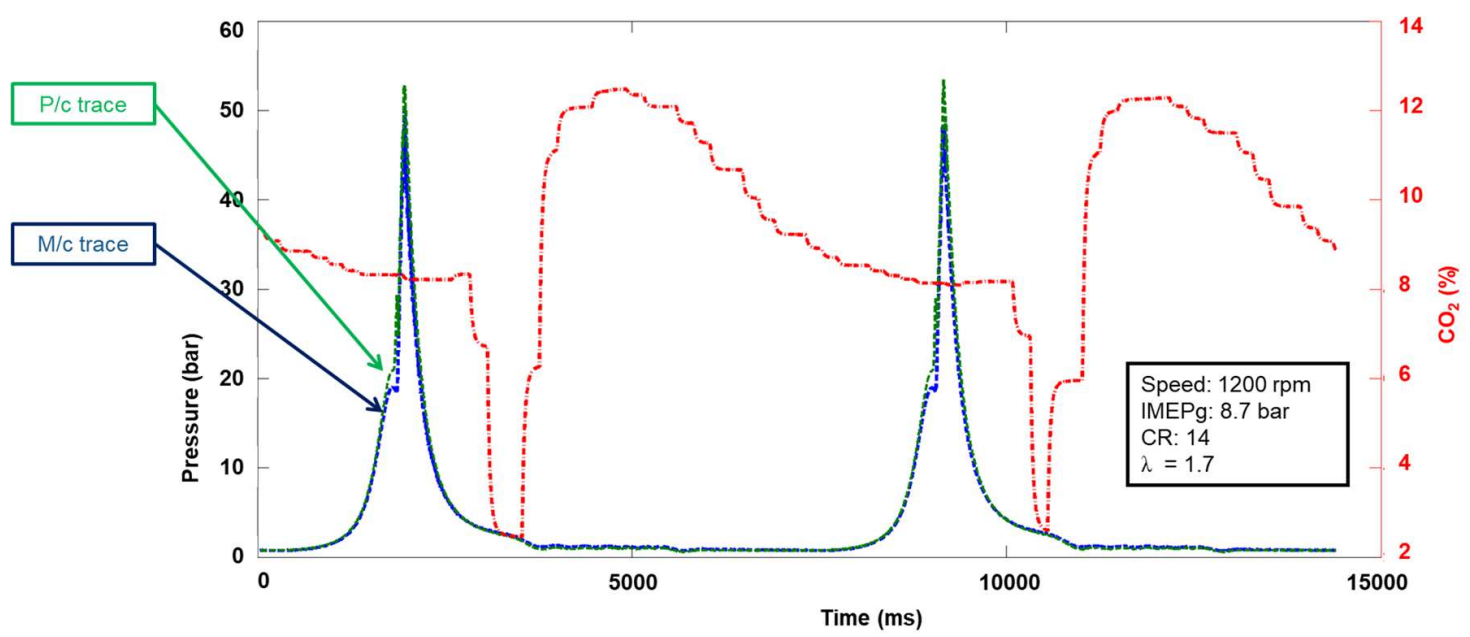

Figure 12. $\mathrm{CO}_{2}$ evolution in the engine as measured through the pre-chamber sample port; $1200 \mathrm{rpm}, 8.7$ bar IMEP, $\lambda=1.7$.

In order to evaluate the influence of pre-chamber fuel injection parameters on pre-chamber residual gas fraction, the engine was operated at lambda $=1.4$, a stable condition regardless of whether or not fuel is being injected directly into the pre-chamber. As is shown in Fig. 13, residual fraction decreases appreciably when fuel is injected directly into the pre-chamber. The residual fraction continues to decrease as the injected fuel quantity is increased. Figure 14 includes a contour graph showing residual fraction trends with pre-chamber fuel injection angle and quantity. While there appears to be little sensitivity to the timing of the injection event, the sensitivity to quantity of fuel injection is apparent. It is likely that the addition of the fuel mass either displaces the dominant residual content at the time of injection, or has a more a complex impact on the completeness of pre-chamber combustion that has yet to be detected. This data suggests that the addition of pre-chamber fuel, even at a constant main chamber lambda, is an effective means by which to reduce the potentially negative impact of residual fraction on prechamber combustion. 


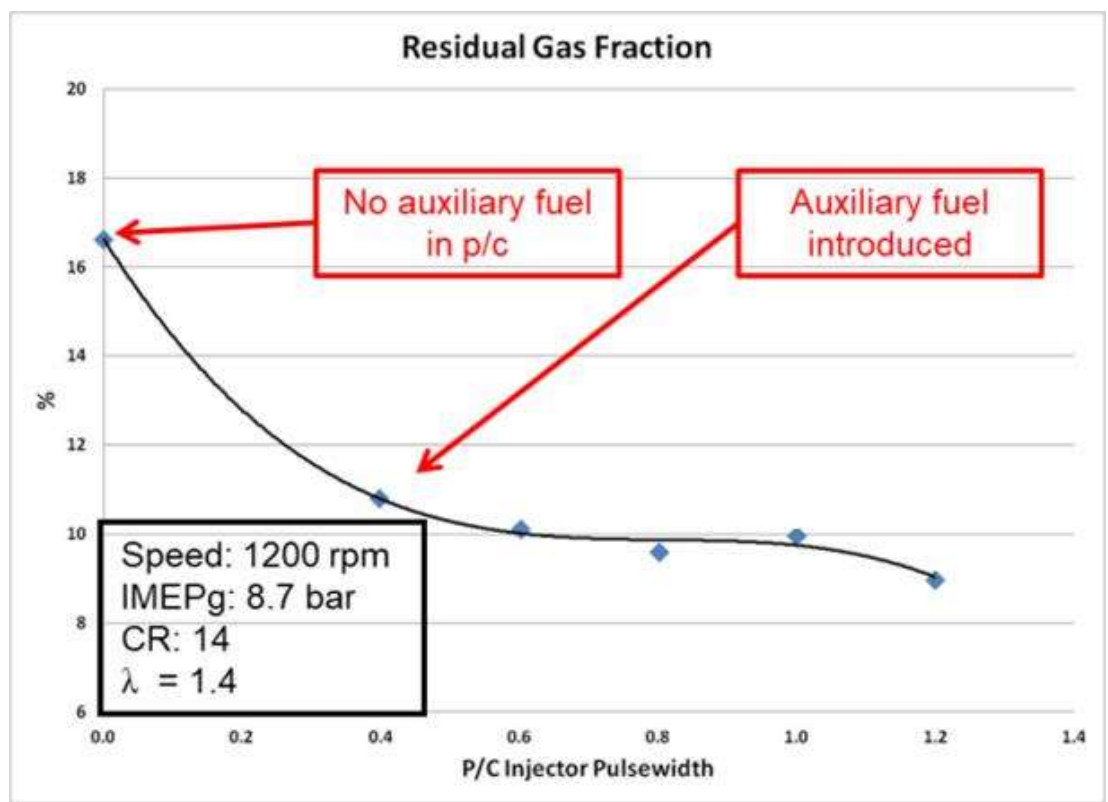

Figure 13. Residual fraction trends with pre-chamber fuel quantity at a representative condition; $1200 \mathrm{rpm}, 8.7$ bar IMEP, $\lambda=1.4$.
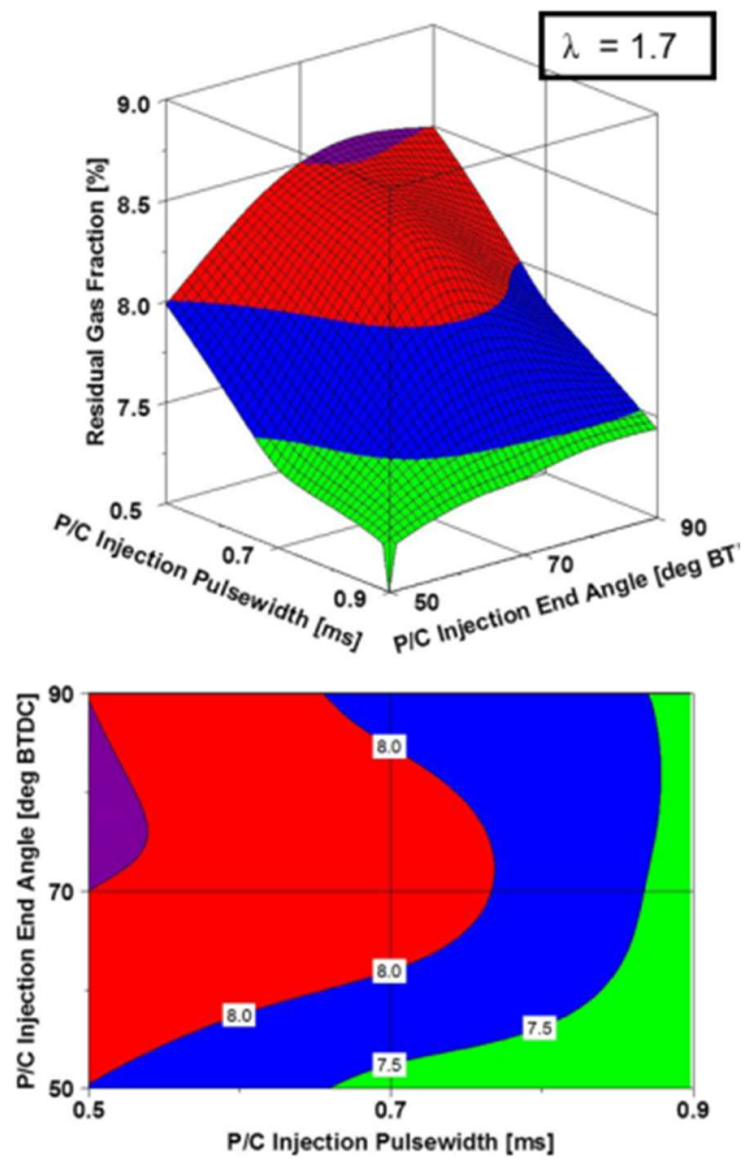
Figure 14. Residual fraction trends with pre-chamber fuel quantity and end of injection angle at a representative condition; $1200 \mathrm{rpm}, 8.7 \mathrm{bar}$ IMEP, $\lambda=1.4$.

\section{Steady State Low Load Operation}

In order to provide correct airflow to maintain acceptable lambda values in the cylinder at low loads, the engine is heavily throttled. As has been established, pre-chambers are reliant on the intake process to facilitate the exchange of residual burned gas from the previous cycle with oxygen-carrying fresh charge. This gas exchange process is pressure-driven and so shifts in this pressure dynamic have a bearing on the proportion of residual gas that is displaced with fresh charge. The reduced intake pressure resulting from heavily throttled operation therefore fails to adequately drive this gas exchange process, producing a pre-chamber with lower proportional oxygen content than is present at less throttled part load conditions. The lower proportional oxygen content present in the pre-chamber is then not adequately mitigated by the pre-chamber filling process that occurs during the compression stroke. The lack of oxygen results in erratic combustion in the pre-chamber, increasing the likelihood of misfires and a corresponding degradation in combustion stability.

Active pre-chambers have the flexibility to both operate lean in the main chamber and to introduce fuel directly in the pre-chamber. Lean operation provides excess oxygen in the main chamber, increasing the oxygen proportion in the pre-chamber during the compression stroke. To account for this dilution, fuel is then injected directly into the pre-chamber. Data from the measured residual fraction experiment suggests that direct fuel injection in the pre-chamber provides an added advantage that can be exploited at low load conditions: the physical displacement of residuals through the introduction of high pressure fuel.

Figure 15 shows the increase in stable low load extension possible with enleanment. The combustion efficiency challenges associated with burning in a low charge density environment are exacerbated by overly lean operation, as is evidenced by inferior low load extension at lambda $=1.7$ vs. lambda $=1.5$, indicating that there is an optimal lambda that balances $\mathrm{O}_{2}$ filling requirements and combustion efficiency. 

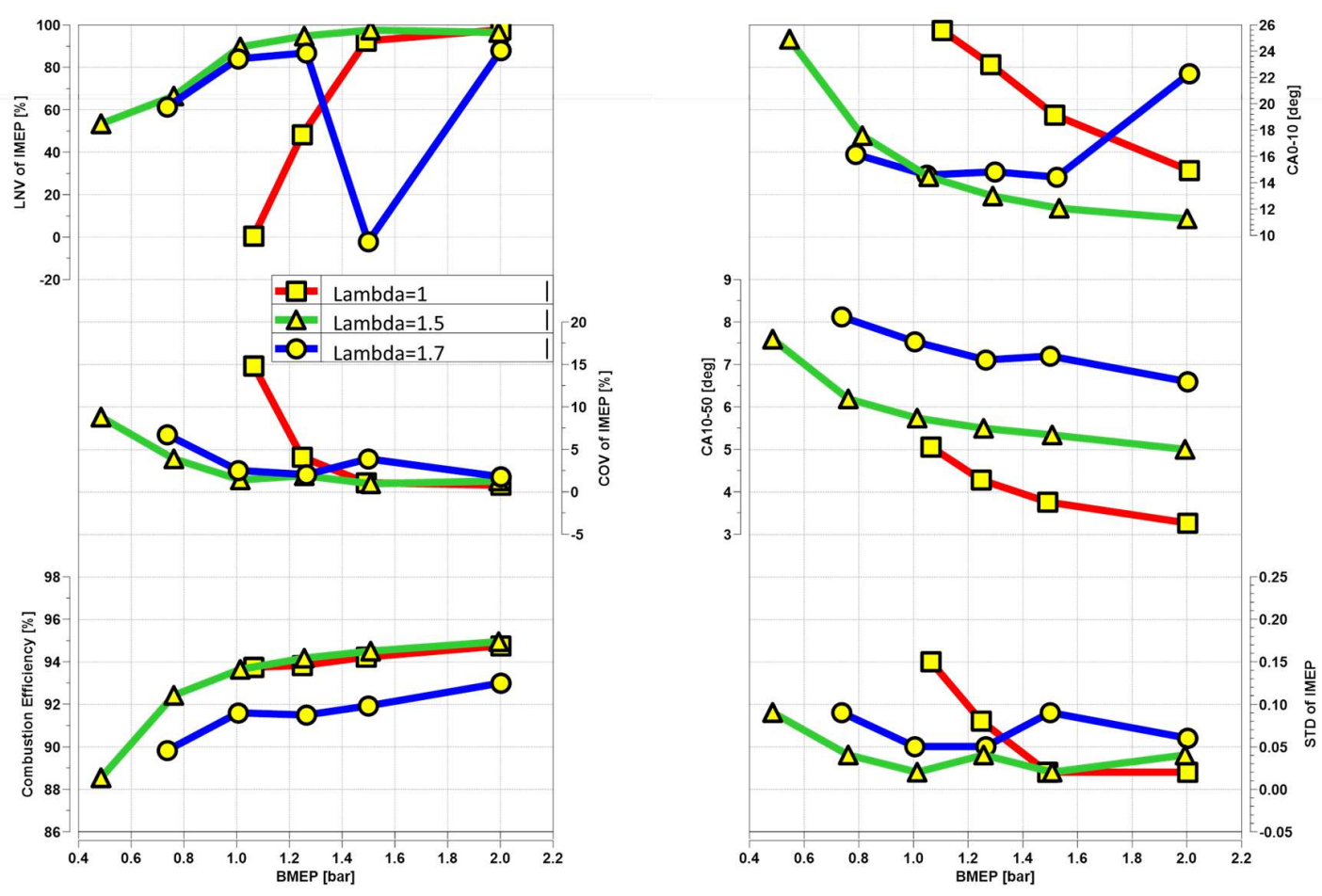

Figure 15. Stability trends at steady state 850rpm low load operation.

\section{Torque Reserve at Idle Operation}

Idle operation is performed at low speed $(<1000 \mathrm{rpm})$ and low or zero load. A requirement for idle is retarded spark timing. At an idle condition there is an anticipation of sudden torque demand from the operator. The most rapid means by which to increase torque at this condition is to advance spark timing from a retarded location to a location advanced of top dead center (TDC). This is due to the engine controller's ability to adjust spark timing on a cycle-by-cycle basis. This rapid advancement in spark timing corresponds to an equally rapid increase in torque.

The acknowledged pre-chamber spark retard limitation does manifest in MJI. Figure 16 demonstrates the severe deterioration in spark retard capability with decreasing engine load, to the extent that at 2 bar BMEP, the engine is incapable of retarding spark timing beyond TDC. This level of spark retard provides only minimal torque reserve when applied to an idle condition. 

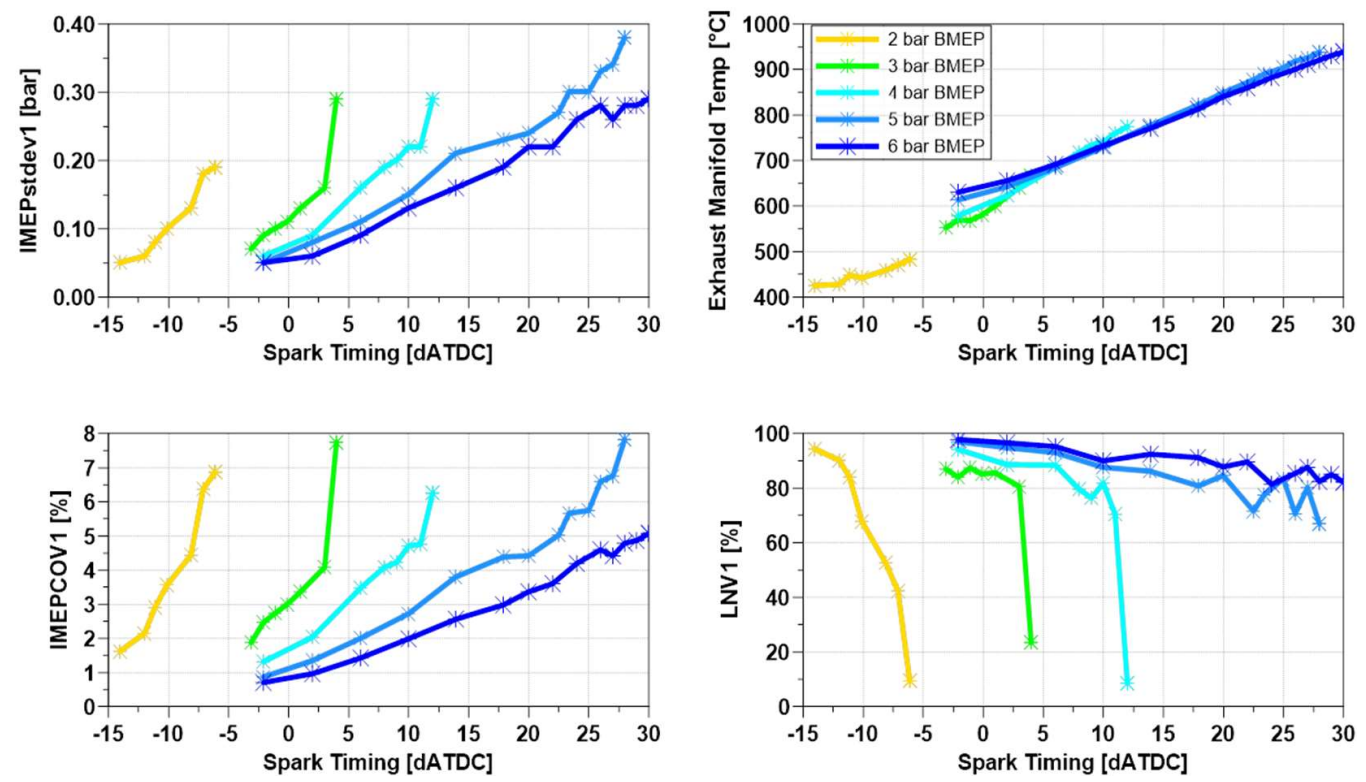

Figure 16. Spark retard trends with load at 1500rpm, lambda=1, warm engine conditions.

As in the case of low load steady state operation, the active system carries the flexibility of operating at a range of lambda values. This offers an advantage for idle operation as well. Fuel injection quantity, similarly to spark timing, can also be adjusted by the engine controller on a cycle-by-cycle basis. However, throttles cannot be adjusted on a cycle-by-cycle basis, so it is not feasible to adjust throttle and fuel quantity simultaneously to accommodate rapid torque demand. Because the active system can operate at a range of stable lambda values at the speed and load necessary for idle, this lambda tolerance can be coupled with the existing minimal spark retard capability to provide ample torque reserve (Fig. 17). Sudden torque demand would therefore manifest as a rapid advancement of spark timing and, simultaneously, a rapid increase in fuel quantity injected.

Figure 18 demonstrates the typical relationship of BMEP to CA50 retard at a constant lambda of 1.5 in the jet ignition engine. BMEP reduces as CA50 is retarded beyond the typical maximum brake torque phasing of 8-10 degrees after TDC (dATDC). Figure 19 demonstrates the relationship of BMEP to enleanment at a constant air flow condition. A constant throttle position maintains air flow, and fuel flow is reduced in order to achieve the target lambda. As a result, BMEP reduces with enleanment. The jet ignition engine operates over a wide lambda range in this case, and the linearity of the trend is maintained. 


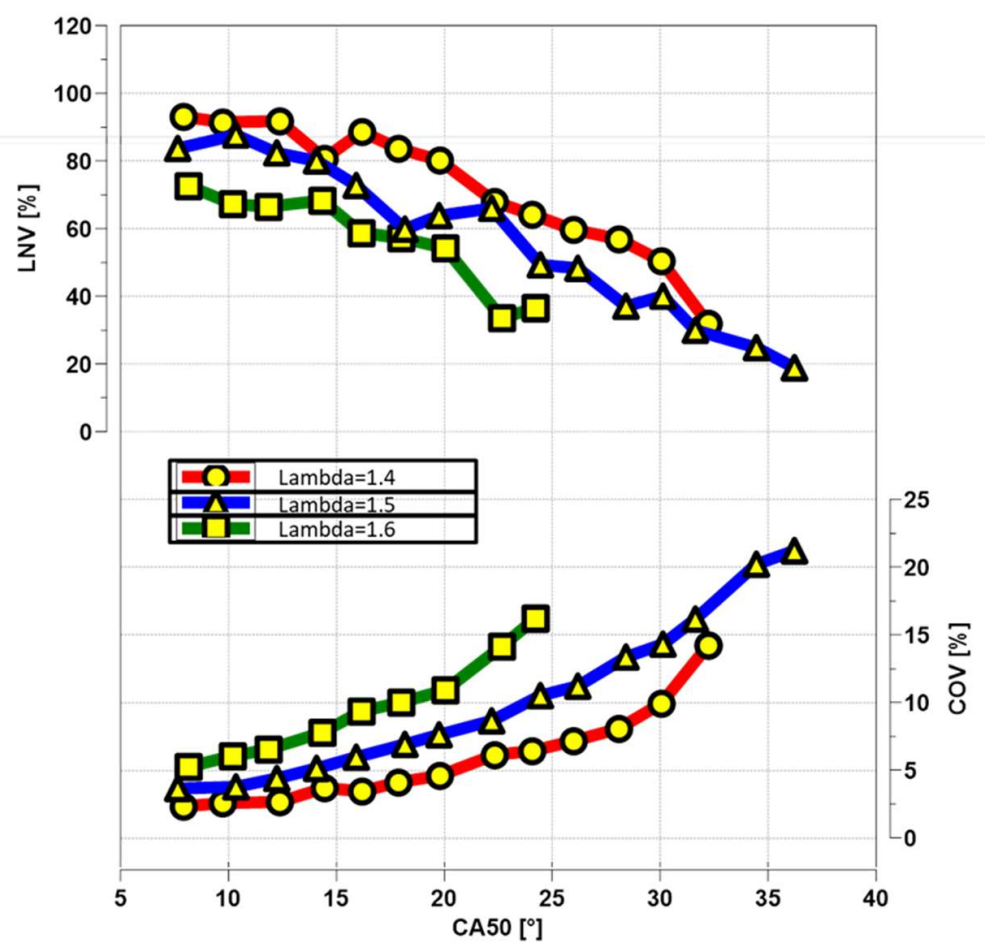

Figure 17. CA50 trends with load at 850rpm, 1 bar BMEP.

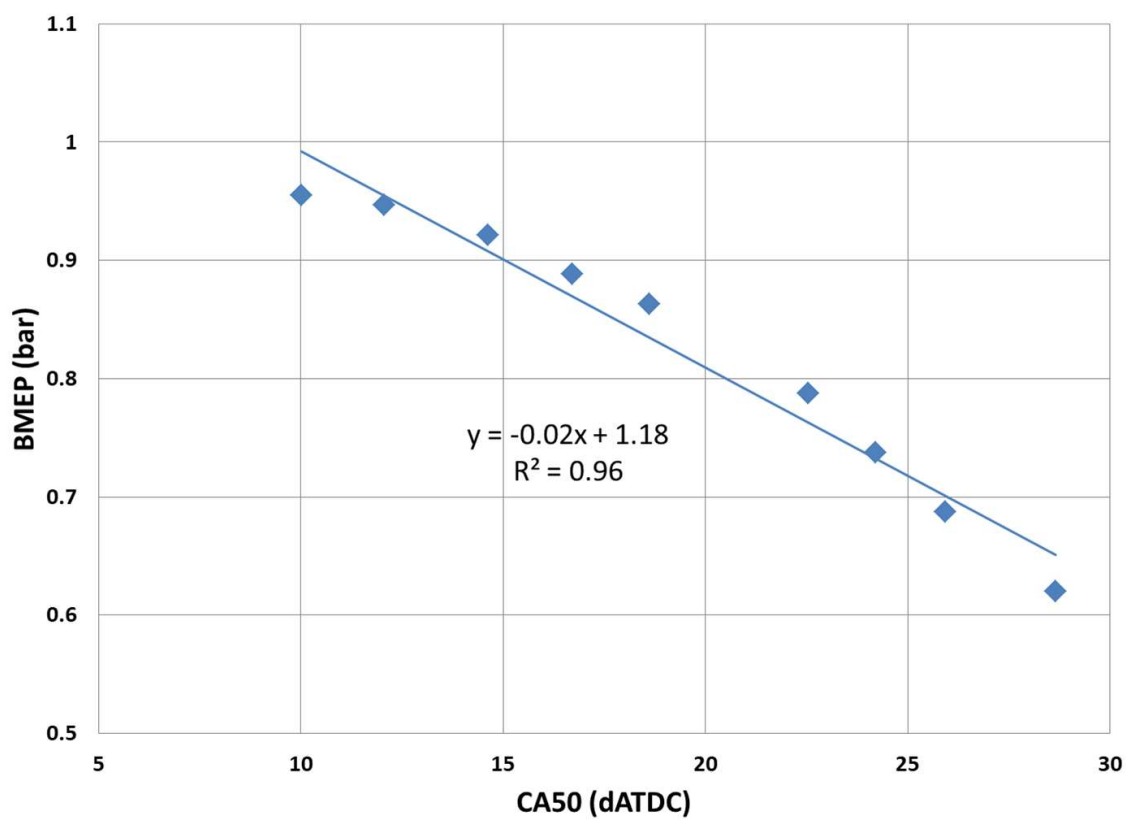

Figure 18. Change in BMEP with retarding CA50 at 850rpm, lambda $=1.5$, constant air flow. 


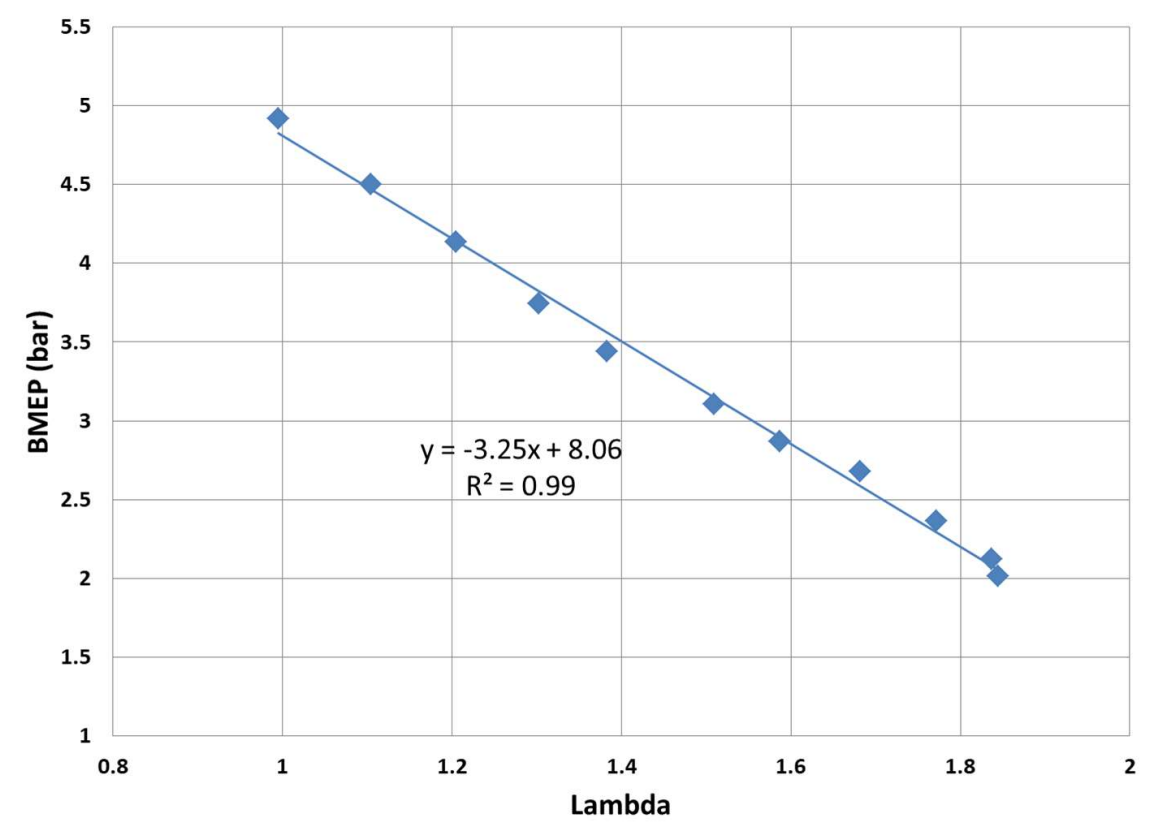

Figure 19. Change in BMEP with enleanment at 850rpm, CA50 $=8 \mathrm{dATDC}$, constant air flow.

Torque reserve requirements of modern SI engines translate to approximately a 20 crank angle degree window of CA50 retard (from 10-30 dATDC) maintaining a lowest normalized value (LNV) of indicated mean effective pressure (IMEP) above 70\% [25]. According to the trend presented in Fig. 18, this CA50 window corresponds to 0.4 bar BMEP, assuming constant speed. Considering only the data presented in Fig. 17 and using $\mathrm{LNV}=70 \%$ as a lower limit, the jet ignition engine lambda and CA50 window corresponds to 1.25 bar BMEP. Active jet ignition therefore can overcome the spark retard limitation by using lambda tolerance in conjunction with spark retard to accommodate stable idle operation and required torque reserve, with potentially superior performance to modern SI engines. Widening the lambda range considered can increase torque reserve further, but spikes in engine-out $\mathrm{NO}_{\mathrm{x}}$ in the near-lean region may negate this widening.

\section{CSSR Operation}

The most impactful challenge posed by the low load spark retard limitation concerns the ability to heat the aftertreatment catalyst upon cold start. The tailpipe emissions produced by vehicles are vastly more significant during the startup phase prior to catalyst light-off than they are at any other point in a legislated drive cycle. Catalysts require heat input to work effectively. Prior to achieving a high temperature light-off condition a large proportion of the engine-out emissions pass through un-catalyzed or uncaptured to the tailpipe. Aggressive warm up of the catalyst is therefore critical to ensuring that the vehicle can meet legislated emissions requirements. The common solution to ensure rapid heat input to the catalyst is to retard spark timing to such a degree that combustion occurs exclusively during the expansion stroke. The much later burning process results in both increased exhaust temperature and increased exhaust flow. The latter results from the non-optimal combustion phasing requiring de-throttling to compensate for the poor thermal efficiency. This poor thermal efficiency is purposeful since a large proportion of the combustion process has minimal to no contribution to torque and instead is used largely to 
generate heat. Spark retard, and its ability to generate high exhaust enthalpy, therefore is an essential element of CSSR operation, which makes pre-chambers' nominal lack thereof a major concern.

Data in Fig. 16 is shown at warm oil and coolant temperatures which are not representative of the CSSR condition. Figure 20 demonstrates the further degradation in performance when fluids are conditioned to 20 degrees Celsius.
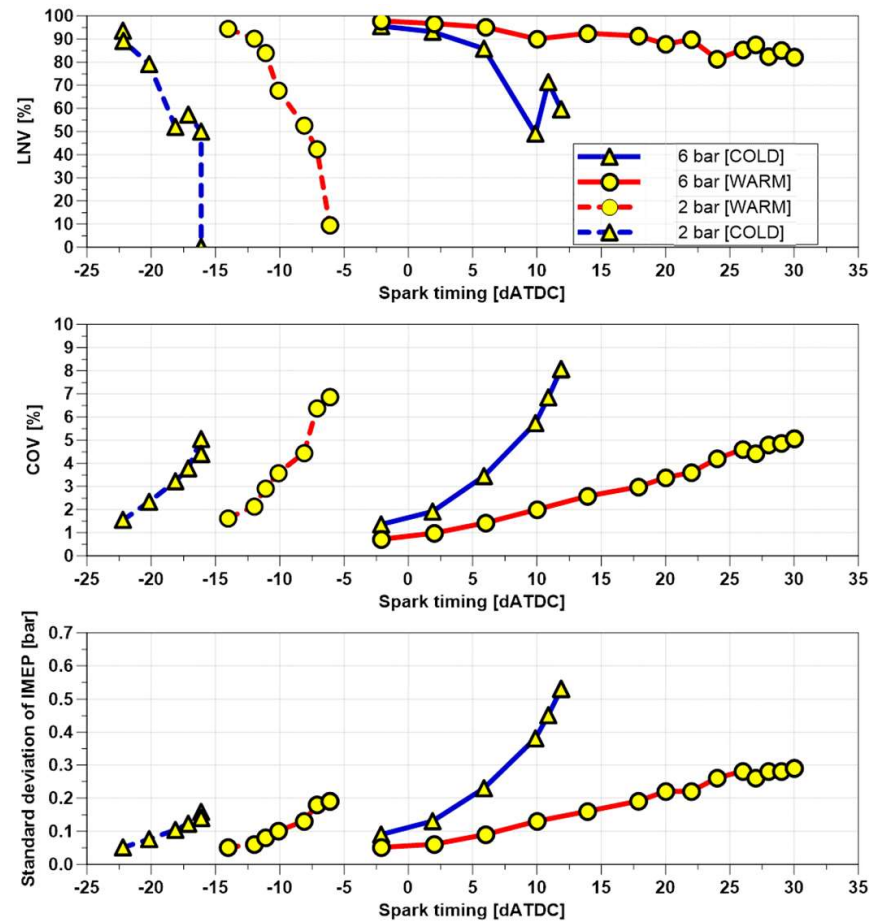

Figure 20. Spark retard trends at warm and cold fluid conditions, $1200 \mathrm{rpm}$.

To properly address this issue, an examination of the failure mode is necessary. With jet ignition engines, different segments of the burn curve provide distinct information about combustion progress:

- Early burning, captured in the CA0-10 duration, encompasses the pre-chamber combustion process from spark through time of radical jet introduction into the main chamber, as well as the ignition process in the main chamber [26].

- Mid-burning, reflected in the CA10-50 duration, encompasses the immediate post-jet ignition process and therefore still bears the influence of jet characteristics such as velocity and reactivity.

- Late burning, CA50-90, occurs long after the jet ignition process has concluded and is therefore largely uninfluenced by characteristics of pre-chamber combustion or the resulting jets.

An examination of the different burn duration segments (Fig. 21) shows linear trends observed in burn duration versus spark timing. These durations are shorter with MJI compared to the SI engine, which is counterintuitive to the spark retard limitation result, as reduced burn duration at 
common conditions should indicate available headroom to continue retarding spark timing. However inspection of the standard deviation of these burn durations indicates an increasing instability with MJI as spark timing is retarded. In this case, the 300 -cycle average burn duration provides no indication of the instability. It is also telling that the instability is present in all three burn duration segments, including CA0-10. This implies that the pre-chamber combustion event is experiencing infrequent misfires or partial burns which cause the main chamber to misfire.

Pre-chamber combustion instability can have several causes including variable mixture preparation conditions or variable heat transfer scenarios. Here the ability of the active system to operate with fuel injected directly into the pre-chamber was again exploited. Auxiliary fuel injection provides direct control over both the fuel quantity and its relative location, thereby mitigating some variability in mixture preparation. In order to prevent over-fueling, the engine is operated lean. Figure 22 compares the spark retard capability of the SI engine, MJI at lambda=1 with no direct pre-chamber fuel, and MJI at lambda $=1.4$ with fuel injected into the pre-chamber. It should be noted that MJI at lambda=1.4 with no auxiliary fuel added to the pre-chamber cannot achieve stable combustion at this condition. In the lambda $=1.4$, fueled pre-chamber configuration however, the MJI engine was able to operate at a retarded spark timing identical to that of the SI engine. The combustion instability present under lambda $=1$ conditions is no longer present with lean operation. 

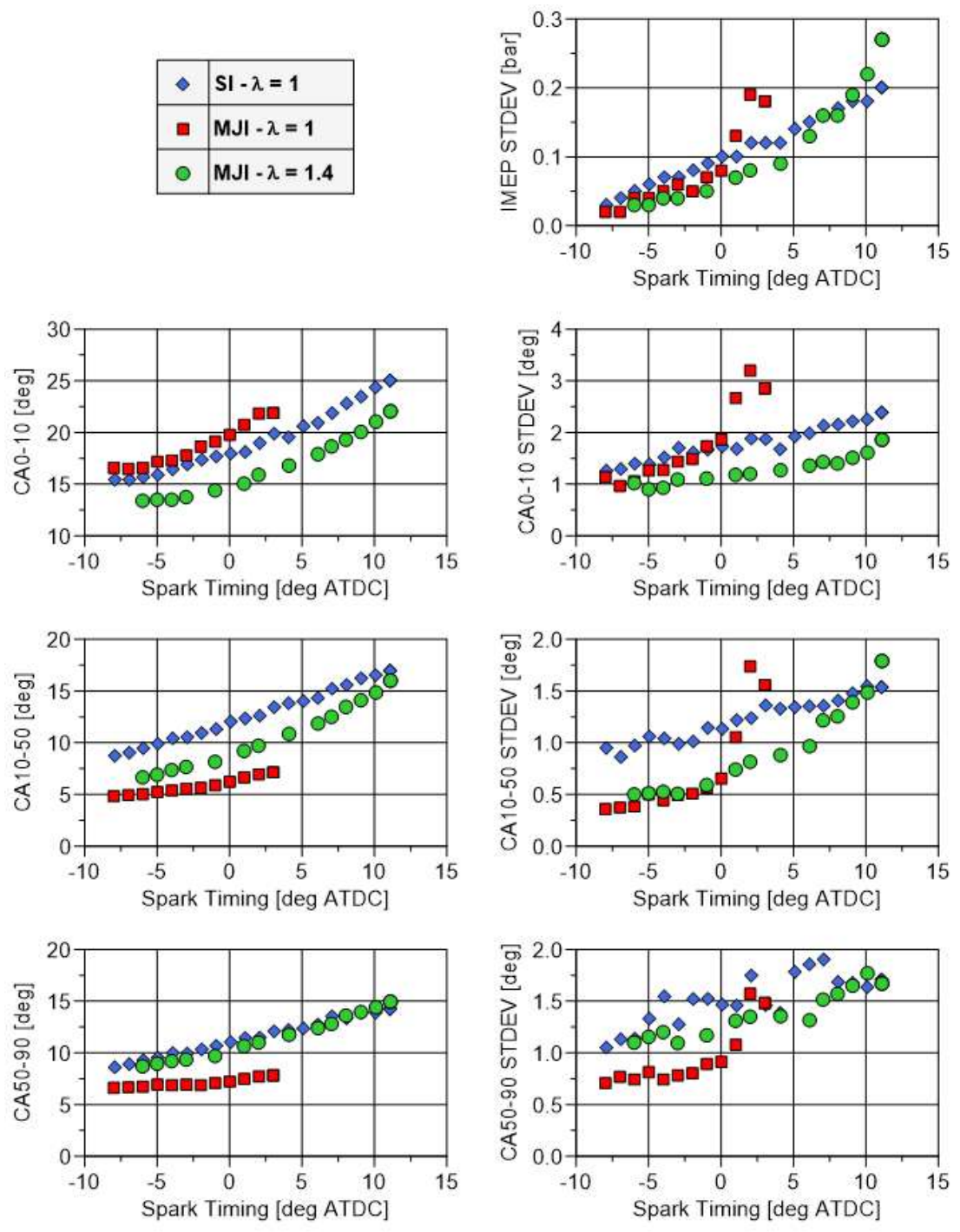

Figure 21. Spark retard trends at 1500rpm, 2 bar net mean effective pressure (NMEP), 20 degree Celsius fluid temperature. 

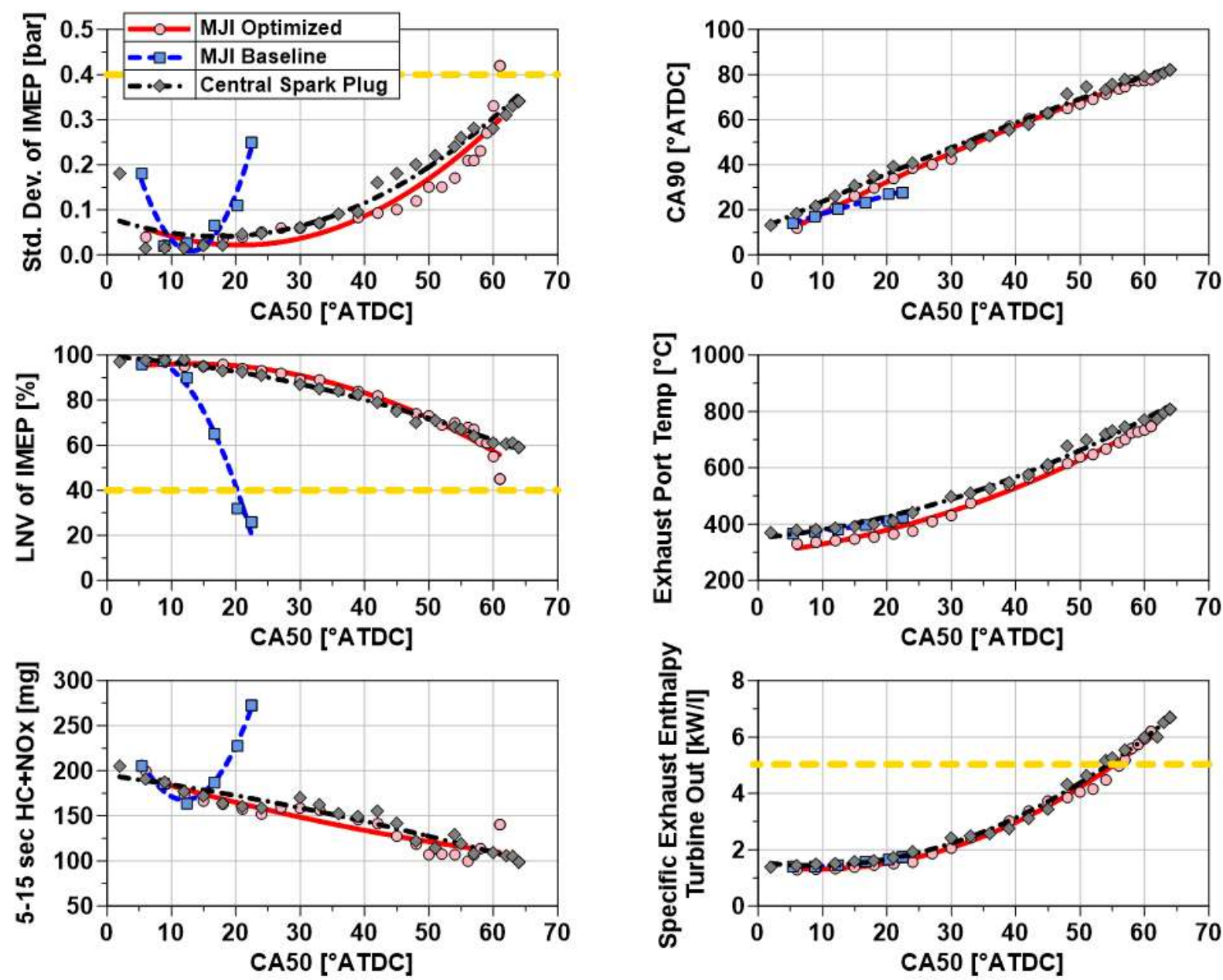

Figure 22. Comparison of relevant catalyst heating trends with CA50 at 1500rpm, 2 bar NMEP, 20 degree Celsius fluid temperature for baseline SI engine, non-optimized MJI engine at lambda $=1$ with no auxiliary fueling, and optimized MJI engine at lambda=1.15 with auxiliary fueling.

The ability to adjust lambda is used to minimize engine-out emissions during this period. A calculated 10 second cumulative mass of $\mathrm{HC}$ and $\mathrm{NO}_{\mathrm{x}}$ emissions is presented in Figure 23. Enleanment produces counter $\mathrm{HC}$ and $\mathrm{NO}_{\mathrm{x}}$ trends, as is evident in Fig. 20. Beyond the lambda $=$ 1.2 condition, $\mathrm{NO}_{\mathrm{x}}$ emissions reduce with enleanment due to the reduction in combustion temperatures with increased dilution. Conversely, $\mathrm{HC}$ emissions increase substantially beyond lambda $=1.2$ at this speed and load. The steep increase in $\mathrm{HC}$ emissions is exacerbated by the retarded CA50 of approximately $50 \mathrm{dATDC}$ leading to a high degree of incomplete combustion. The minimum cumulative mass is clearly evident in the near-lean region, at approximately lambda $=1.15$ 


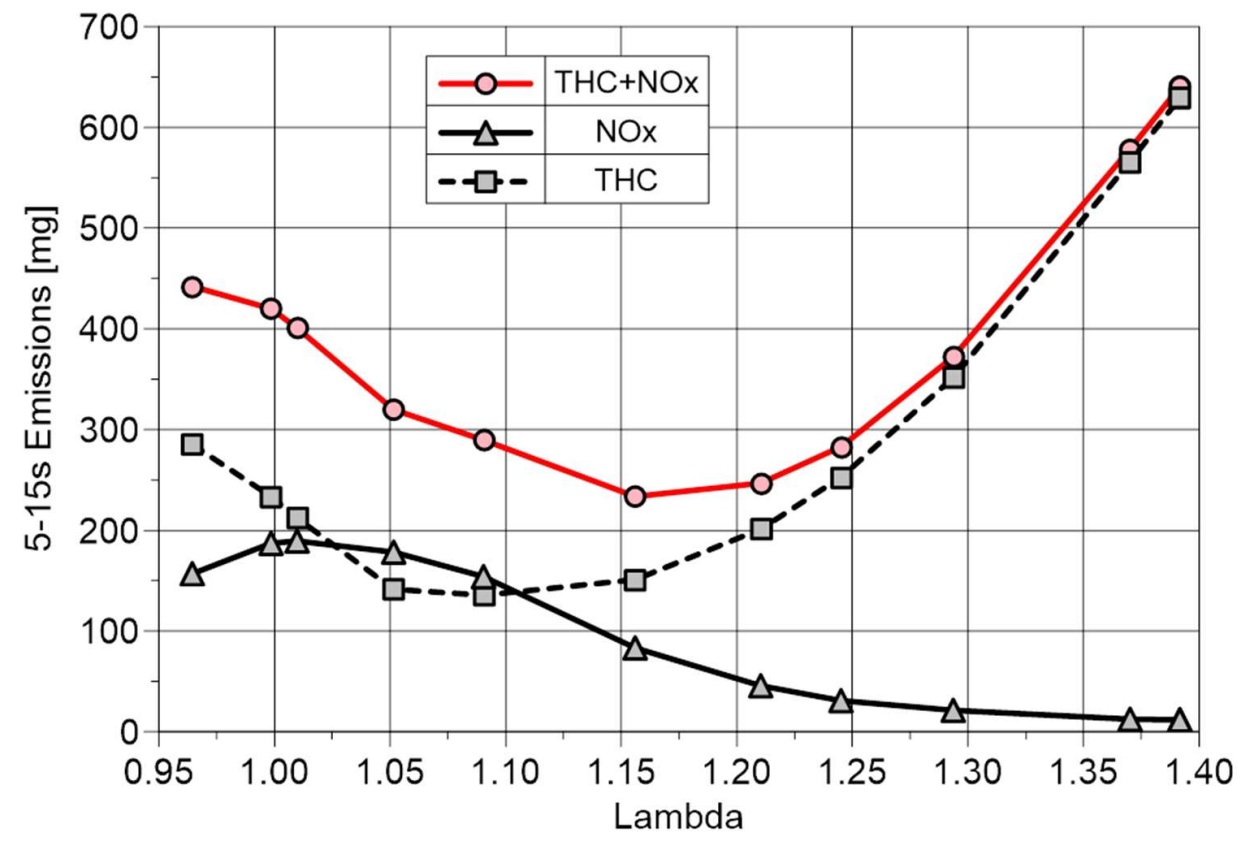

Figure 23. Emissions trends with lambda at 1500rpm, 2 bar NMEP, CA50 $=50$ dATDC, 20 degree Celsius fluid temperature.

The effect of charge motion on jet ignition performance is not well understood, particularly its impact at retarded spark timing. For these experiments, the effect of charge motion was evaluated at a representative low load condition at a stoichiometric lambda. Figure 24 shows distinct differences in combustion stability amongst the charge motion variants across the spark timing range presented. The addition of tumble provides the lowest standard deviation of IMEP during spark retard operation, though spark timing range is not improved. The comparatively poor pre-chamber LNV of the swirl case, with only muted impact on the main chamber LNV implies that the swirl case produces erratic pre-chamber combustion. 

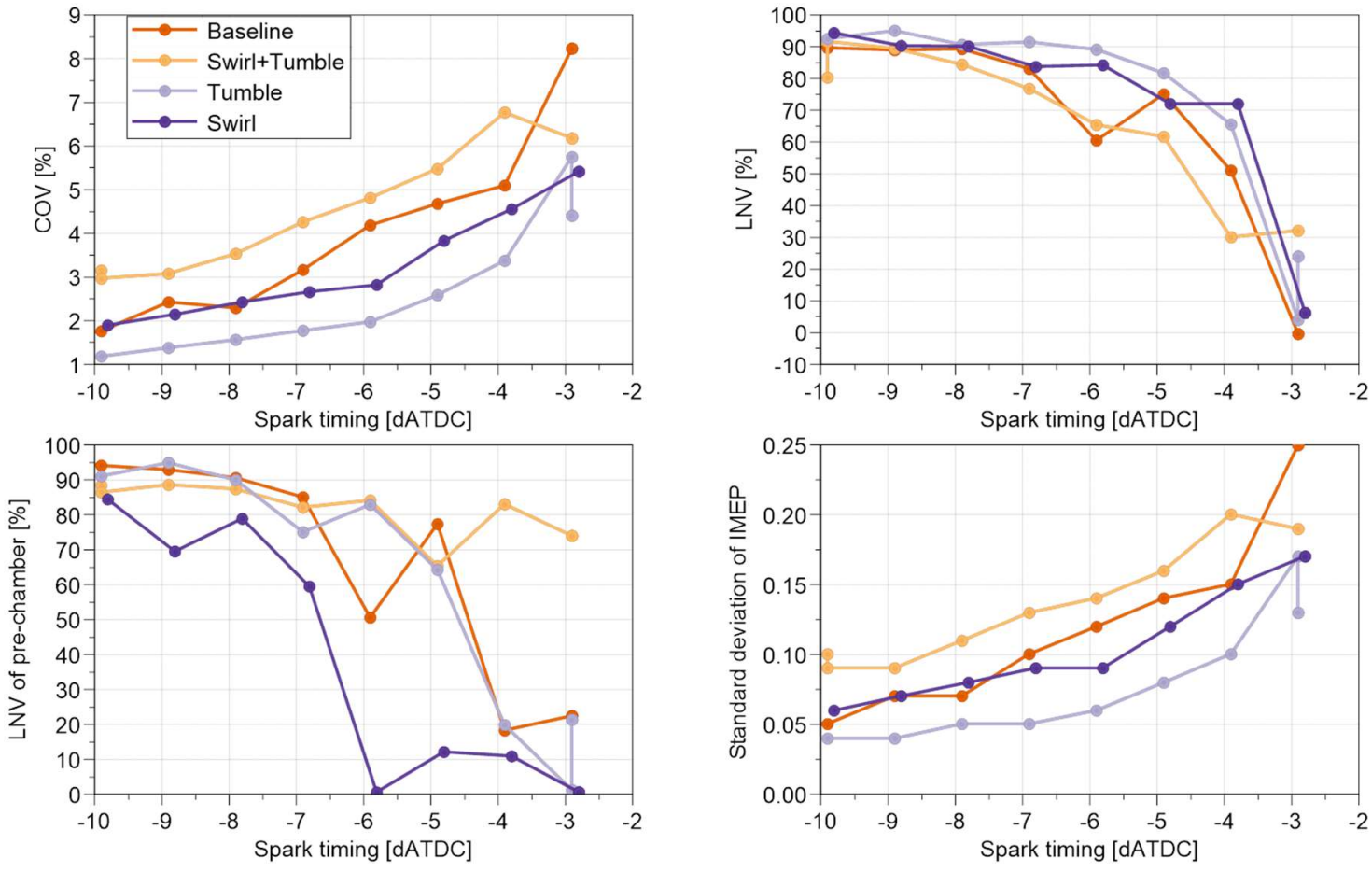

Figure 24. Various combustion stability metrics vs. spark timing at 2000rpm, 2 bar BMEP, lambda $=1$.

The baseline and tumble variants clearly show a significant increase in thermal efficiency across the spark timing range versus the two swirl-based variants (Fig. 25). This translates to the combustion efficiency results as well (Fig. 26). The swirl-only variant displays anomalous results in indicated thermal versus brake thermal efficiency, which are also reflected in elevated exhaust enthalpy over the spark timing range. This is possibly due to an abnormally elevated gross IMEP level necessary to maintain the target BMEP level for the swirl-only variant. No charge motion variant, however, exhibits higher combustion efficiency than that of the baseline variant. With no improvement in spark retard capability or emissions at stoichiometric conditions, the addition of charge motion offers no clear advantages in CSSR operation, as reflected in both spark retard capability and exhaust enthalpy. An upcoming study will focus on the effect of charge motion addition on CSSR performance across the spark timing range at lean conditions. 

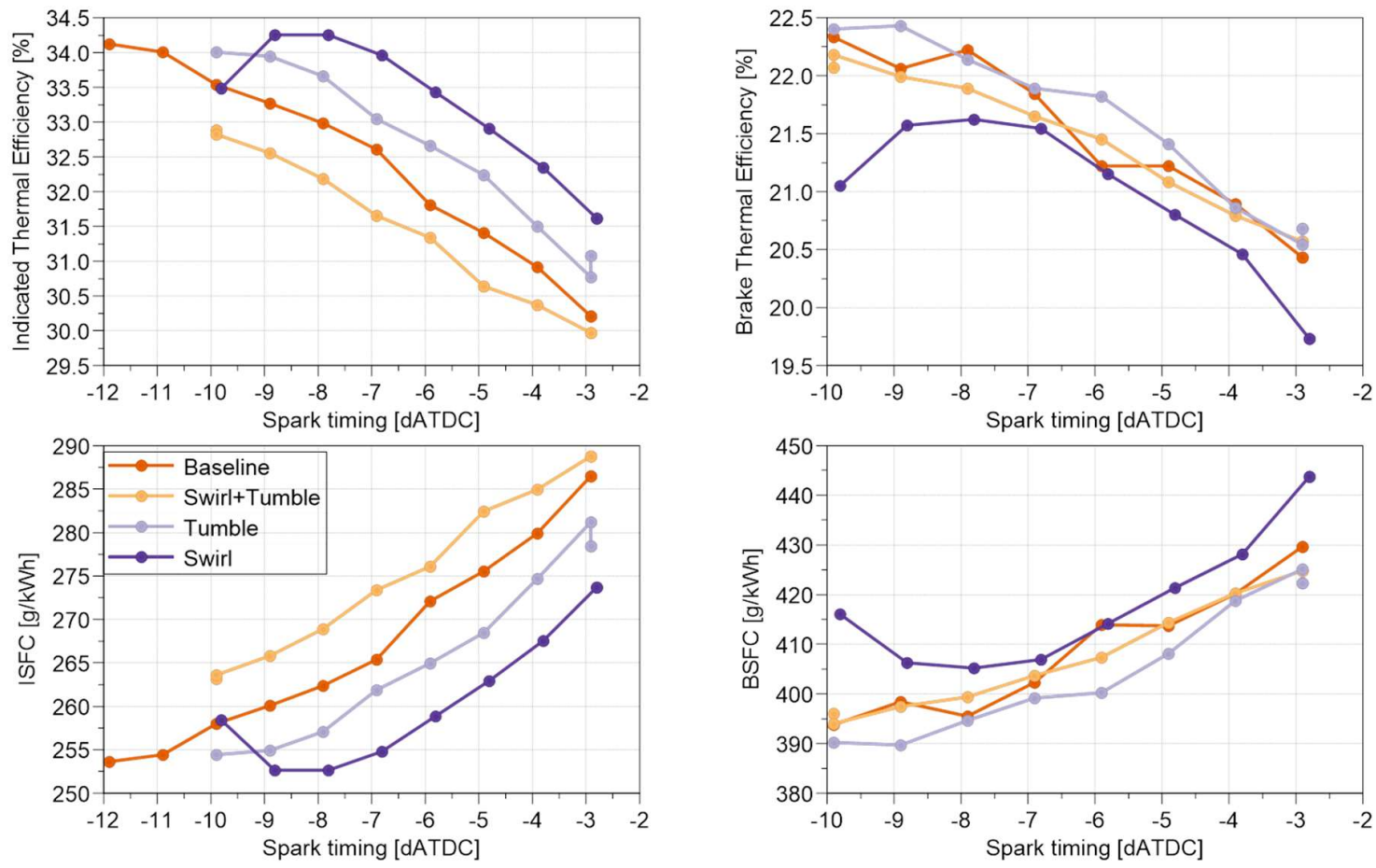

Figure 25. Efficiency vs. spark timing at 2000rpm, 2 bar BMEP, lambda=1.
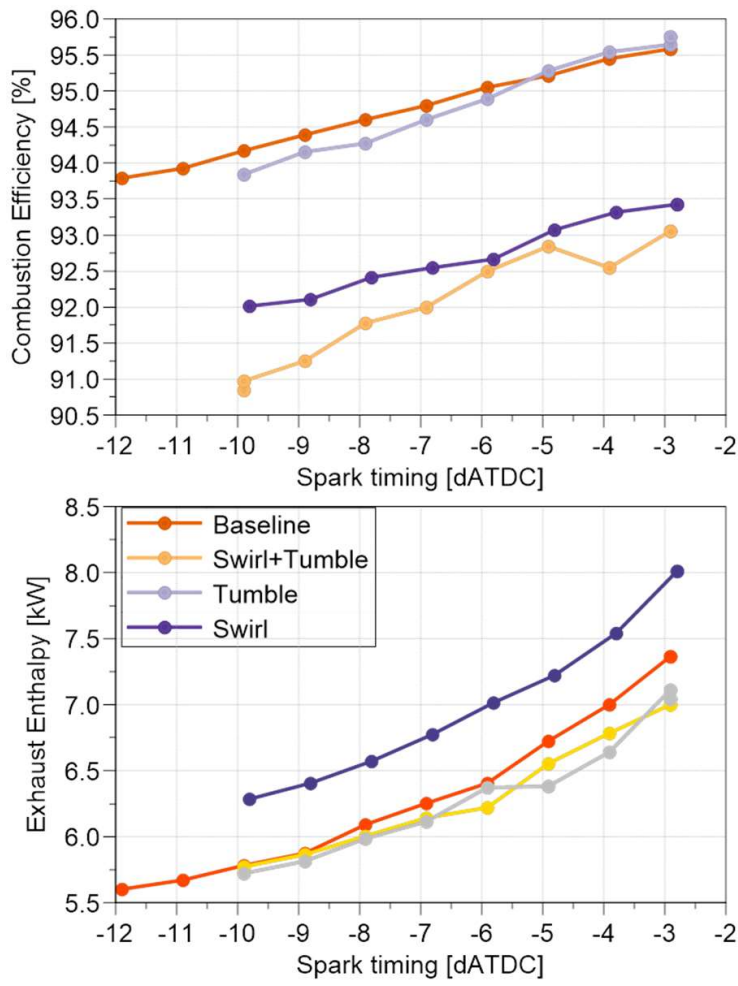

Figure 26. Combustion efficiency and exhaust enthalpy vs. spark timing at 2000rpm, 2 bar BMEP, lambda=1. 


\section{CONCLUSION}

Pre-chamber combustors have been proven to enable high levels of homogeneous dilution well beyond typical SI engine lean limits. Stable highly dilute combustion can improve thermal efficiency to levels competitive with peak achievements in advanced combustion research.

A traditional weakness of pre-chamber concepts, particularly jet igniters, is load engine performance. This is manifested as poor combustion stability under heavily throttled conditions and lack of adequate spark retard. Considering the diversity of operation required of modern engines, these challenges have prevented more widespread adoption of jet ignition in current engines. The results of this study offer hypotheses as to the root cause of this limitation, and show that the flexibility inherent in active jet ignition systems with finely controlled pre-chamber fuel metering presents avenues to mitigate these challenges. Specifically, moderate lean operation aids in passive scavenging of pre-chamber residuals and the $\mathrm{O}_{2}$ filling process, increasing combustion stability compared to stoichiometric combustion. Similarly, the dilution tolerance of active jet ignition enables cycle-by-cycle lambda modulation to supplement the moderate spark retard under idle conditions, thereby exceeding the torque reserve requirement. Finally, the pre-chamber injection event provides more consistency to the pre-chamber mixture preparation conditions. This in turn reduces pre-chamber combustion variation and the resulting main chamber variation as the burning event is retarded in order to provide sufficient exhaust enthalpy for CSSR operation.

Leveraging these results, the experimental engine was able to achieve low load operating results consistent with those of modern SI engines. These results represent progress towards enabling high efficiency jet ignition operation through the entire engine operating map, overcoming a significant impediment to wider commercial adoption of the technology.

\section{AUTHOR INFORMATION}

\section{Corresponding Author}

*University of Nottingham, University Park, Nottingham, NG7 2RD, UK

\section{Present Addresses}

†Present address: MAHLE Powertrain LLC, 14900 Galleon Ct., Plymouth, Michigan 48170, USA

\section{Author Contributions}

The manuscript was written through contributions of all authors. All authors have given approval to the final version of the manuscript.

\section{Funding Sources}

This research was supported through funds provided by MAHLE Powertrain, LLC.

\section{REFERENCES}

1) Bunce M, Blaxill H. Sub-200 g/kWh BSFC on a light duty gasoline engine. SAE paper 2016-01-0709, 2016.

2) Bunce $\mathrm{M}$, Blaxill $\mathrm{H}$, Kulatilaka $\mathrm{W}$, et al. The effects of turbulent jet characteristics on engine performance using a pre-chamber combustor. SAE paper 2014-01-1195, 2014. 
3) Quader AA. Lean combustion and the misfire limit. SAE paper 741055, 1974.

4) Husted H, Piock W, Ramsay G. Fuel efficiency improvements from lean stratified combustion with a solenoid injector. SAE paper 2009-01-1485, 2009.

5) Germane G, Wood C, Hess C. Lean combustion in spark-ignited internal combustion engines - a review. SAE paper 831694, 1983.

6) Heywood J. Internal combustion engine fundamentals. New York: McGraw-Hill, 1988.

7) Yamamoto $H$. Investigation on relationship between thermal efficiency and NOx formation in ultra-lean combustion. SAE paper JSAE 9938083, 1999.

8) Dober GG, Watson HC. Quasi-dimensional and CFD modelling of turbulent and chemical flame enhancement in an ultra lean burn S.I. engine. Modeling of SI Engines 2000; SP-1511.

9) Ward M. High-energy spark-flow coupling in an IC engine for ultra-lean and high EGR mixtures. SAE paper 2001-01-0548, 2001.

10) Qiao A, Wu X. Research on the new ignition control system of lean- and fast-burn SI engines. SAE paper 2008-01-1721, 2008.

11) Attard W, Toulson E, Fraser N, et al. A turbulent jet ignition pre-chamber combustion system for large fuel economy improvements in a modern vehicle powertrain. SAE paper 2010-01-1457, 2010.

12) Bureshaid K, Feng D, Zhao H, Bunce M. Combustion and emissions of gasoline, anhydrous ethanol, and wet ethanol in an optical engine with a turbulent jet ignition system. Proceedings of the Institution of Mechanical Engineers, Part D: Journal of Automobile Engineering 2019; 233(13): 3528-3537.

13) Toulson E, Schock H, Attard W. A review of pre-chamber initiated jet ignition combustion systems. SAE paper 2010-01-2263, 2010.

14) Sens M, Binder E, Reinicke P-B, Riess M, Stappenbeck T, Woebke M. Pre-chamber ignition and promising complementary technologies. 27th Aachen Colloquium Automobile and Engine Technology, 2018.

15) Vedula R, Song R, Stuecken T, Zhu G, Shock H. Thermal efficiency of a dual-mode turbulent jet ignition engine under lean and near-stoichiometric operation. International Journal of Engine Research 2017; 18(10): 1055-1066.

16) Attard W, Blaxill H. A lean burn gasoline fueled pre-chamber jet ignition combustion system achieving high efficiency and low NOx at part load. SAE paper 2012-01-1146, 2012 .

17) Bunce M, Blaxill H, Attard W. Turbulent jet ignition pre-chamber combustion system for spark ignition engines. Patent 9,353,674, USA, 2014.

18) Chinnathambi P, Bunce M, Cruff L. RANS based multidimensional modeling of an ultralean burn pre-chamber combustion system with auxiliary liquid gasoline injection. SAE paper 2015-01-0386, 2015.

19) Brannys S, Gehrke S, Hoffmeyer H, Hentschel L. Maximum efficiency concept of a 1.51 TSI evo for future hybrid powertrains. 28th Aachen Colloquium Automobile and Engine 
Technology, 2019.

20) Cao Y, Li L. A novel closed loop control based on ionization current in combustion cycle at cold start in a gdi engine. SAE paper 2012- 01-1339, 2012.

21) Bunce M, Peters N, Subramanyam SKP, et al. Assessing the low load challenge for jet ignition engine operation. In: Proceedings of the Institute of Mechanical Engineers Internal Combustion Engines Conference, Birmingham, UK, 11-12 December 2019.

22) Bassett M, Hall J, Cains T, et al. Dynamic downsizing gasoline demonstrator. SAE Int. J. Engines 2017; 10(3).

23) Bassett M, Hall J, Hibberd B, et al. Heavily downsized gasoline demonstrator. SAE Int. J. Engines 2016; 9(2): 729-738.

24) Bunce M, Blaxill H. Internal combustion engine. Patent 10,458,311, USA, 2018.

25) Cooper A, Harrington A, Bassett M, et al. Application of the passive MAHLE jet ignition system and synergies with miller cycle and exhaust gas recirculation. SAE paper 202001-0283, 2020.

26) Bunce $\mathrm{M}$, Blaxill $\mathrm{H}$. Methodology for combustion analysis of a spark ignition engine incorporating a pre-chamber combustor. SAE paper 2014-01-2603, 2014. 